Supplementary Information

\title{
Chemical and Biochemical Approaches for the Synthesis of Substituted
}

\section{Dihydroxybutanones and Di-, and Tri-Hydroxypentanones}

Derar Al-Smadi, ${ }^{\dagger} \|$ Thilak Reddy Enugala, ${ }^{\dagger}$ Vadim Kessler, ${ }^{\ddagger}$ Anil Ranu Mhashal, ${ }^{\dagger}$ S. C. Lynn Kamerlin, ${ }^{\dagger}$ Jan Kihlberg, ${ }^{\dagger}$ Thomas Norberg, ${ }^{\dagger}$ and Mikael Widersten ${ }^{* \dagger}$

† Department of Chemistry - BMC, Uppsala University, Box 576, SE-751 23 Uppsala, Sweden

¿ Department of Molecular Sciences, Swedish University of Agricultural Sciences, Box 7015,

SE-750 07 Uppsala, Sweden

*E-mail: mikael.widersten@kemi.uu.se

|| Current address: Department of Chemistry, Faculty of Science, An-Najah National University, Nablus, Palestine.

\section{Contents:}

Supplementary experimental details:

\section{Supplementary tables:}

Table S1. Mobile phase composition for chiral separation of aldol enantiomers over Chiralpak AS-H . $\mathrm{S} 3$

Table S2. H2-H3 NMR coupling constants

Supplementary figures:

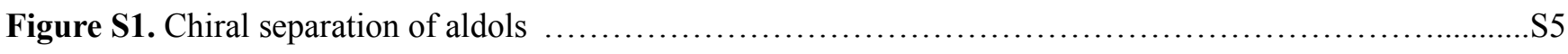

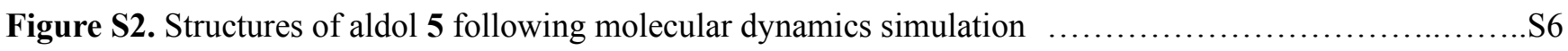

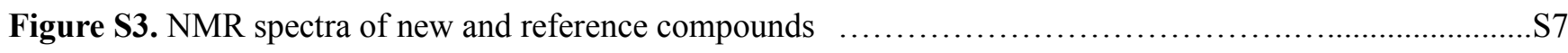

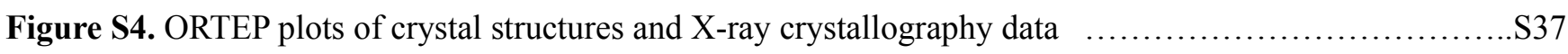

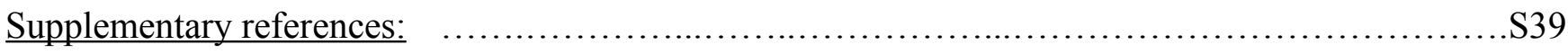




\section{$\underline{\text { Supplementary experimental details }}$}

\section{X-ray crystallography}

$(2 R, 3 R)-5: \mathrm{C}_{17} \mathrm{H}_{18} \mathrm{O}_{4}, \mathrm{M}_{\mathrm{w}}=286.31 \mathrm{Da}$, Monoclinic, Space group P2(1), $a=5.6203(3), b=8.9365(5), c$ $=14.7908(10) \AA, \beta=92.213(5)^{\circ}, V=742.33(83) \AA^{3}, Z=2, D_{\text {calc }}=1.281 \mathrm{~g} / \mathrm{cm}^{3} .3747$ independent reflections $(2926$ observed with $\mathrm{I}>2 \operatorname{sigma}(\mathrm{I}))$ were collected until 2 Theta $=58.70^{\circ}$. The refinement converged with least square parameters $\mathrm{R} 1=0.0360$, wR2 $=0.1049$ and GOOF $=0.933$ for the observed and $\mathrm{R} 1=0.0526, \mathrm{wR} 2=0.12198$ and $\mathrm{GOOF}=0.933$ for all reflections .

$(2 R, 3 R)-6: \mathrm{C}_{16} \mathrm{H}_{15} \mathrm{O}_{3} \mathrm{Cl}, \mathrm{M}_{\mathrm{w}}=290.73 \mathrm{Da}$, Orthorhombic, Space group Pben, $a=8.345(3), b=$ 11.250(3), $c=30.833(9) \AA, V=2894.6(15) \AA^{3}, Z=8, D_{\text {calc }}=1.334 \mathrm{~g} / \mathrm{cm}^{3} .2218$ independent reflections $(1754$ observed with $\mathrm{I}>2 \operatorname{sigma}(\mathrm{I}))$ were collected until 2 Theta $=53.96^{\circ}$. The refinement converged with least square parameters $\mathrm{R} 1=0.0343, \mathrm{wR} 2=0.0878$ and $\mathrm{GOOF}=0.901$ for the observed and $\mathrm{R} 1=$ $0.0482, \mathrm{wR} 2=0.0946$ and $\mathrm{GOOF}=0.901$ for all reflections.

$(3 S, 4 R)-12: \mathrm{C}_{11} \mathrm{H}_{13} \mathrm{O}_{3} \mathrm{Cl}, \mathrm{M}_{\mathrm{w}}=228.67 \mathrm{Da}$, Monoclinic, space group $\mathrm{P} 2(1) / \mathrm{n}, a=14.851(15), b=$ 4.703(5), $c=16.195(16) \AA$, beta $=107.694(12) \mathrm{deg}, V=1077.8(19) \AA \wedge 3, Z=4.1944$ independent reflections were collected in the angle interval $2.23<$ Theta $<25.24$ deg with completeness $99.4 \%$. The structure converged at final discrepancy values $\mathrm{R} 1=0.0529$, wR2 $=0.1322$ for 1944 observed reflections with I $>2$ sigma(I). 


\section{$\underline{\text { Supplementary tables }}$}

Table S1. Mobile phase composition for chiral separation over Chiralpak AS-H of aldol enantiomer mixtures following purification of reaction products by reversed-phase HPLC

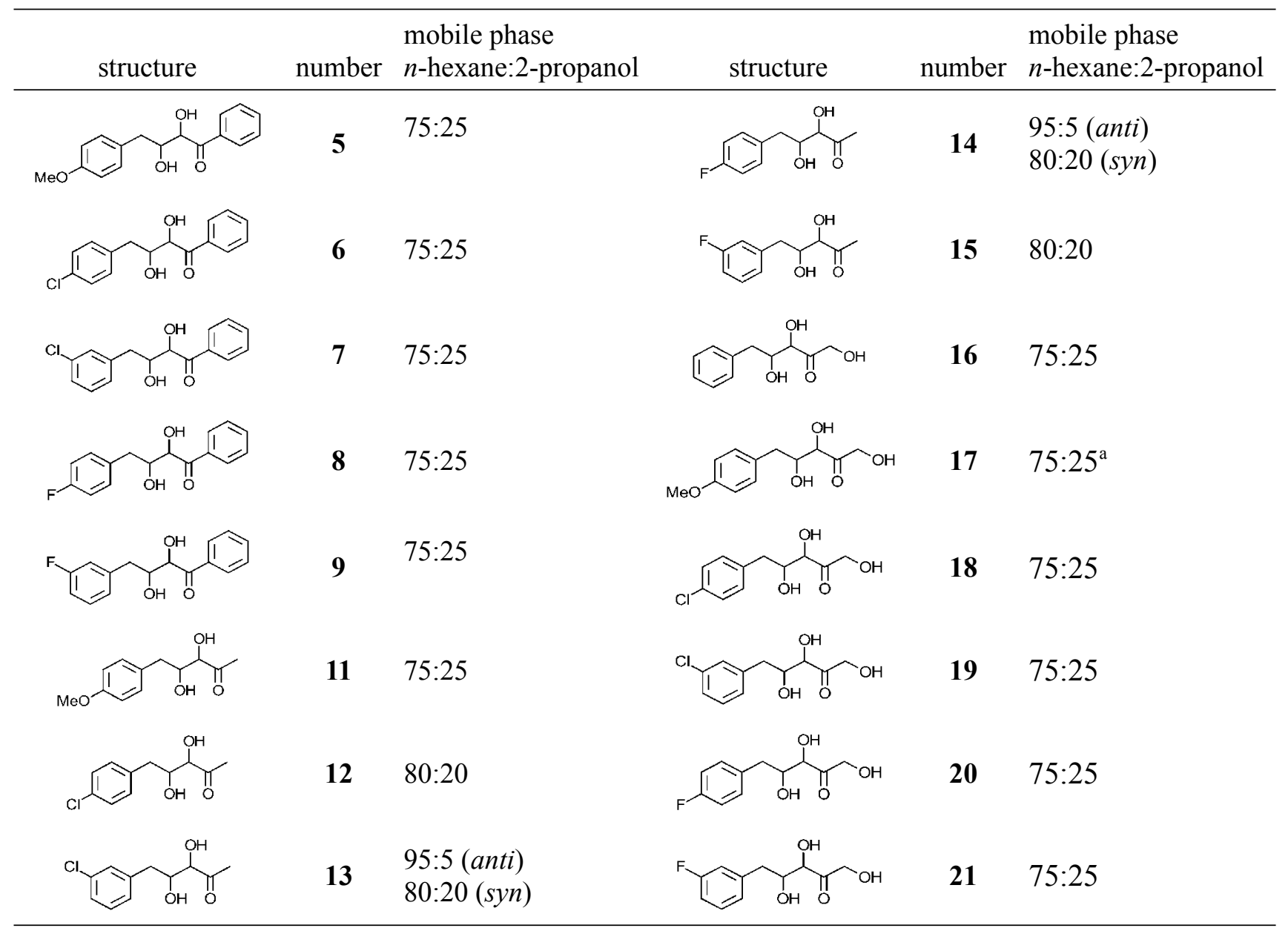

${ }^{a}$ From ref. S1. 
Table S2. H2-H3 coupling constants

\begin{tabular}{cccccc}
\hline compound & $\begin{array}{c}\text { coupling } \\
\text { constant }(\mathrm{Hz})\end{array}$ & $\begin{array}{c}\text { diastereomer } \\
\text { assignment }\end{array}$ & compound & $\begin{array}{c}\text { coupling } \\
\text { constant (Hz) }\end{array}$ & $\begin{array}{c}\text { diastereomer } \\
\text { assignment }\end{array}$ \\
\hline anti-4 & 5.6 & anti & anti-12 & 5.7 & anti \\
syn-4 & 1.6 & syn & syn-12 & 2.0 & syn \\
anti-5 & 5.5 & anti & anti-13 & n.d. & anti \\
syn-5 & 1.6 & syn & syn-13 & 1.9 & syn \\
anti-6 & 5.8 & anti & anti-14 & 5.6 & anti \\
syn-6 & 1.7 & syn & syn-14 & 1.9 & syn \\
anti-7 & 5.8 & anti & anti-15 & n.d. & anti \\
syn-7 & 1.8 & syn & syn-15 & 1.9 & syn \\
anti-8 & 5.7 & anti & syn-16 & $2.0,^{\mathrm{b}} 1.9$ & syn \\
syn-8 & 1.6 & syn & syn-17 & $2.0^{\mathrm{c}}$ & syn \\
anti-9 & 5.8 & anti & syn-18 & 2.1 & syn \\
syn-9 & 1.7 & syn & syn-19 & 2.1 & syn \\
anti-10 & n.d. & anti & syn-20 & 2.0 & syn \\
syn-10 & $1.8,1.9^{\mathrm{b}}$ & syn & syn-21 & 2.1 & syn \\
anti-11 & 5.4 & anti & & & \\
syn-11 & $1.6,2.0^{\mathrm{c}}$ & syn & & & \\
\hline
\end{tabular}

${ }^{a}$ n.d., not determined. ${ }^{b}$ From ref. S2 ${ }^{c}$ From ref. S1. 
$\underline{\text { Supplementary figures }}$
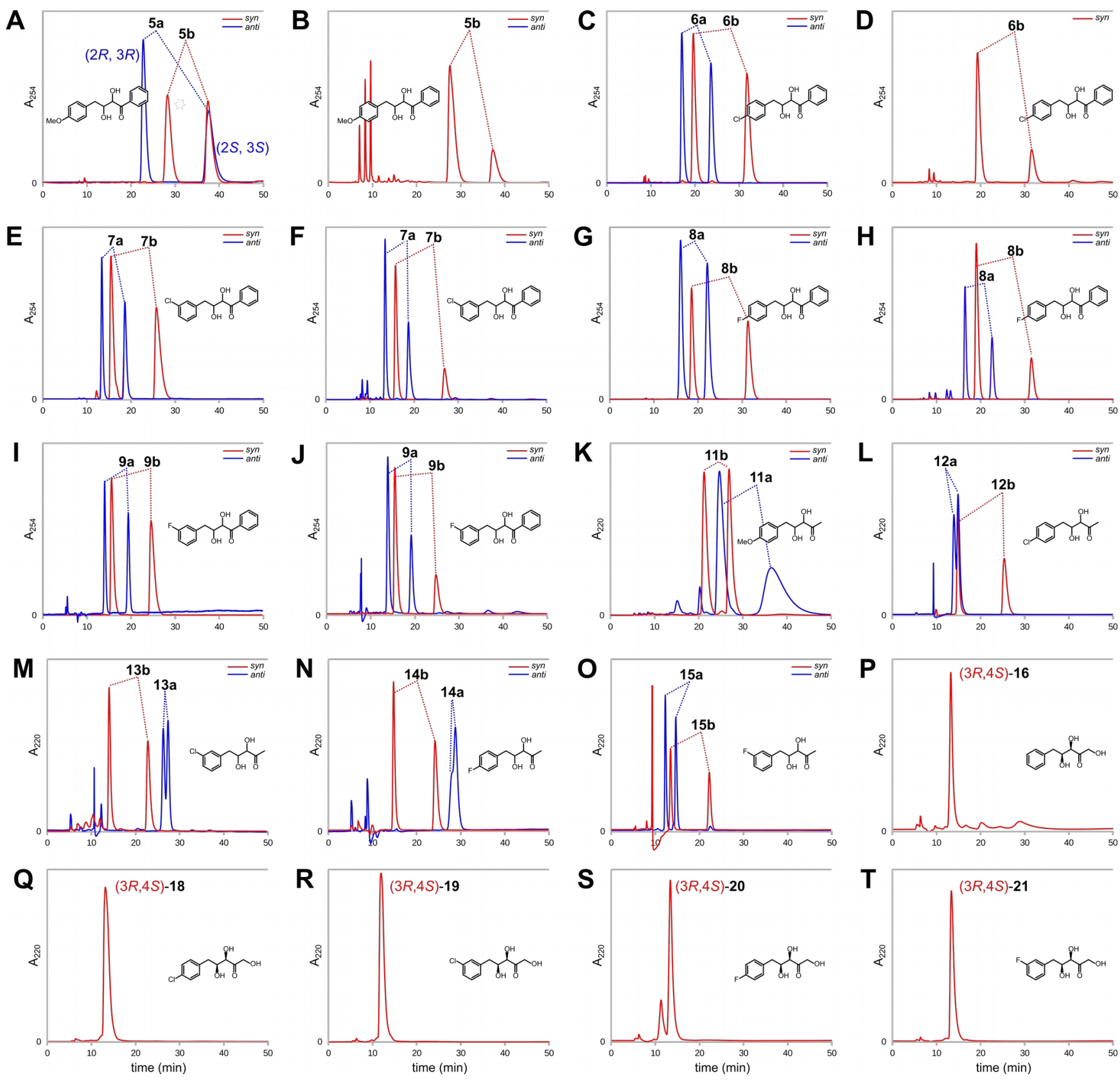

Figure S1. Chiral separation (Chiralpak AS-H) of aldols synthesized in this work. The aldols were synthesized either in the presence of $\mathrm{SmI}_{2}{ }^{\mathrm{S} 3}$ (A, C, E, G, I, K-O), cinchonine ${ }^{\mathrm{S} 4}$ (B, D, F, H and J), or the biocatalyst FSA VG ${ }^{\mathrm{S} 1}$ (P-T) See the main text for experimental details and Table $\mathbf{S} 1$ for composition of the mobile phase. 


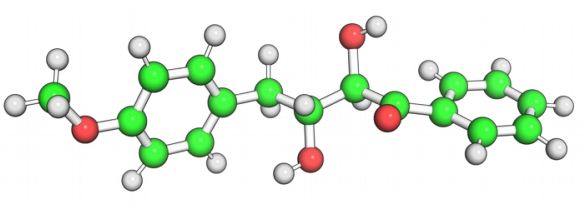

$(2 R, 3 R)-5$

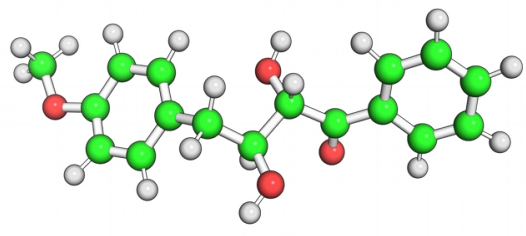

$(2 S, 3 S)-5$

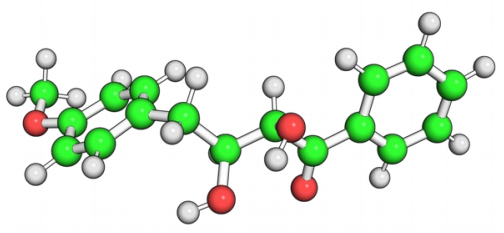

(2R,3S)-5 (H-gauche)

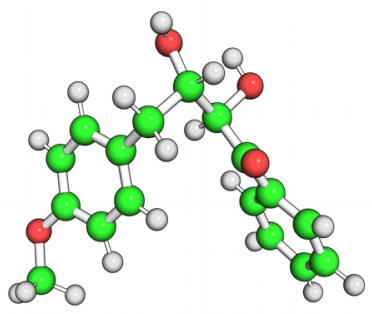

(2R,3S)-5 (H-anti)

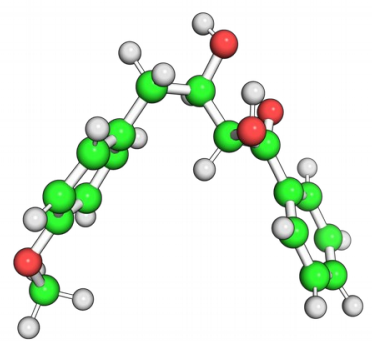

(2S,3R)-5 (H-gauche)

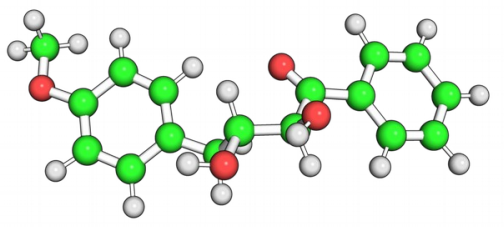

(2S,3R)-5 (H-anti)

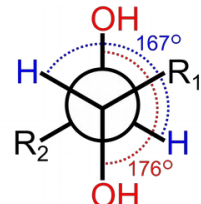

simulated structure

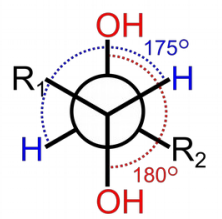

simulated structure

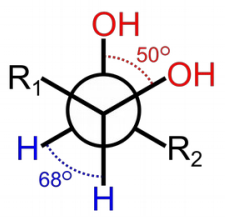

simulated structure

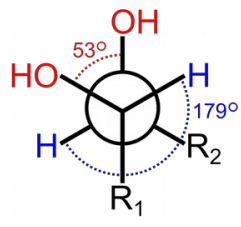

simulated structure

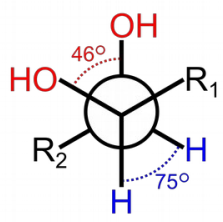

simulated structure

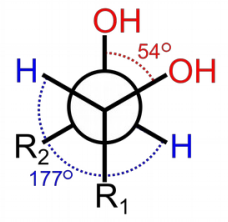

simulated structure

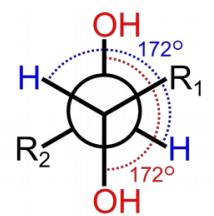

crystal structure<smiles>[R]=[C]C(=O)c1ccccc1</smiles><smiles>[R][C]Cc1ccc(OC)cc1</smiles>

Figure S2. Equilibrium structures of aldol 5 following $5 \mu \mathrm{s}$ molecular dynamics simulations at $300 \mathrm{~K}$. The anti diastereomers $(2 R, 3 R)$ and $(2 S, 3 S)$ equilibrate into one extended conformation with the substituents bound to the chiral carbons placed in anti conformations. These structures are within the error identical to the corresponding conformation of $(2 R, 3 R)-5$ in the crystal structure (Newman projection, top right). The simulated structures of the $s y n$ diastereomers $(2 R, 3 S)$ and $(2 S, 3 R)$ on the other hand, display relatively equal distributions between two distinct conformations, here named as H-gauche and $\mathrm{H}$-anti, where in the former conformation the hydrogen substituents are positioned in a conformation with torsion angles of $\sim 70^{\circ}$, whereas in the $\mathrm{H}$-anti conformations the same hydrogens display torsion angles of $\sim 180^{\circ}$. 
Figure S3. ${ }^{1} \mathrm{H}$ - and ${ }^{13} \mathrm{C}-\mathrm{NMR}$ spectra of new $(5-9,11-15,18-21)$ and reference $(4,10$ and 16) compounds. For conditions and reference values, see "General methods" in the main paper. Note: All compounds, except for 16-21 which were all of $(3 R, 4 S)$ configuration, were racemates, but for simplicity the structure of only one of the two possible enantiomers is drawn in each spectrum.
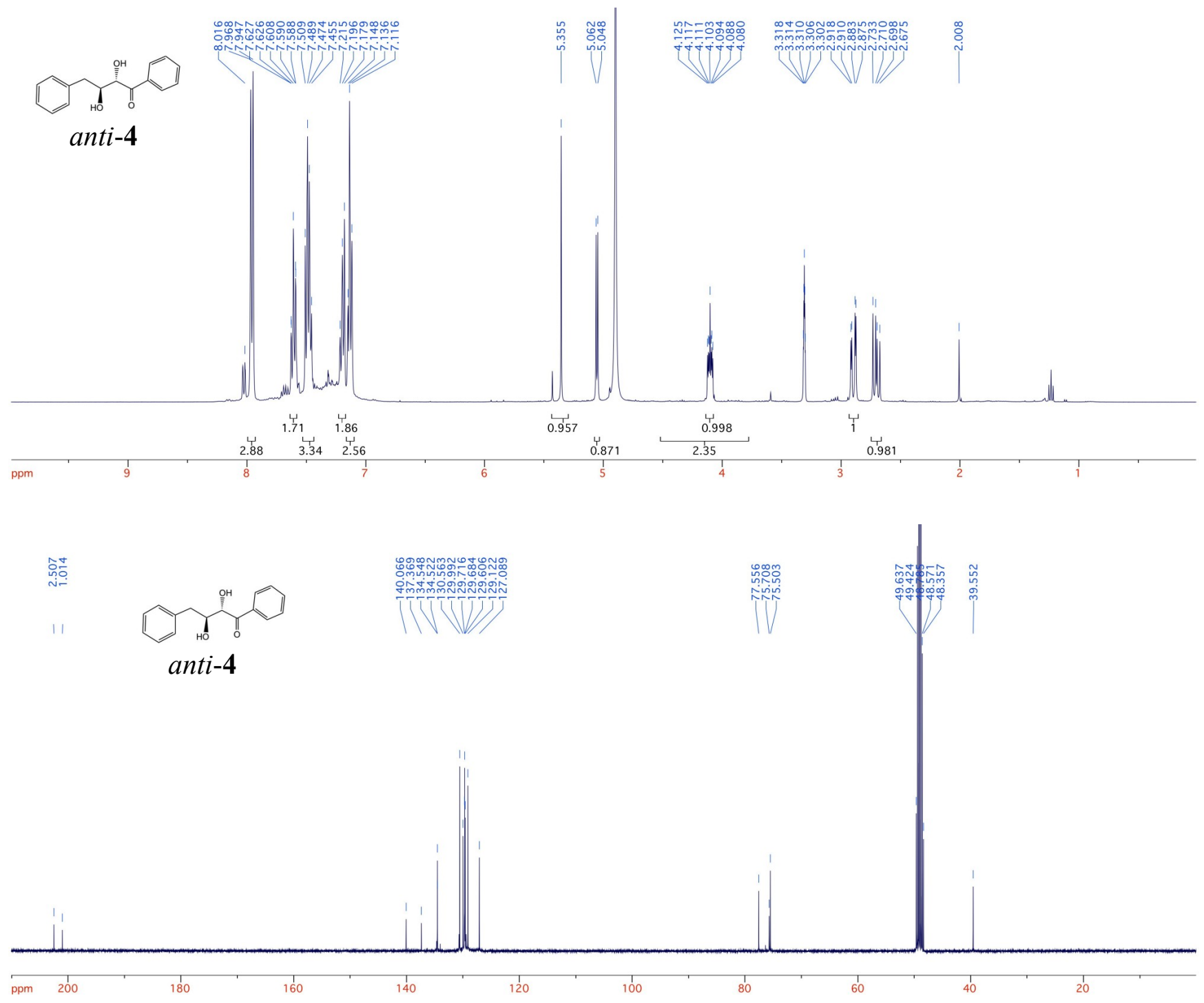

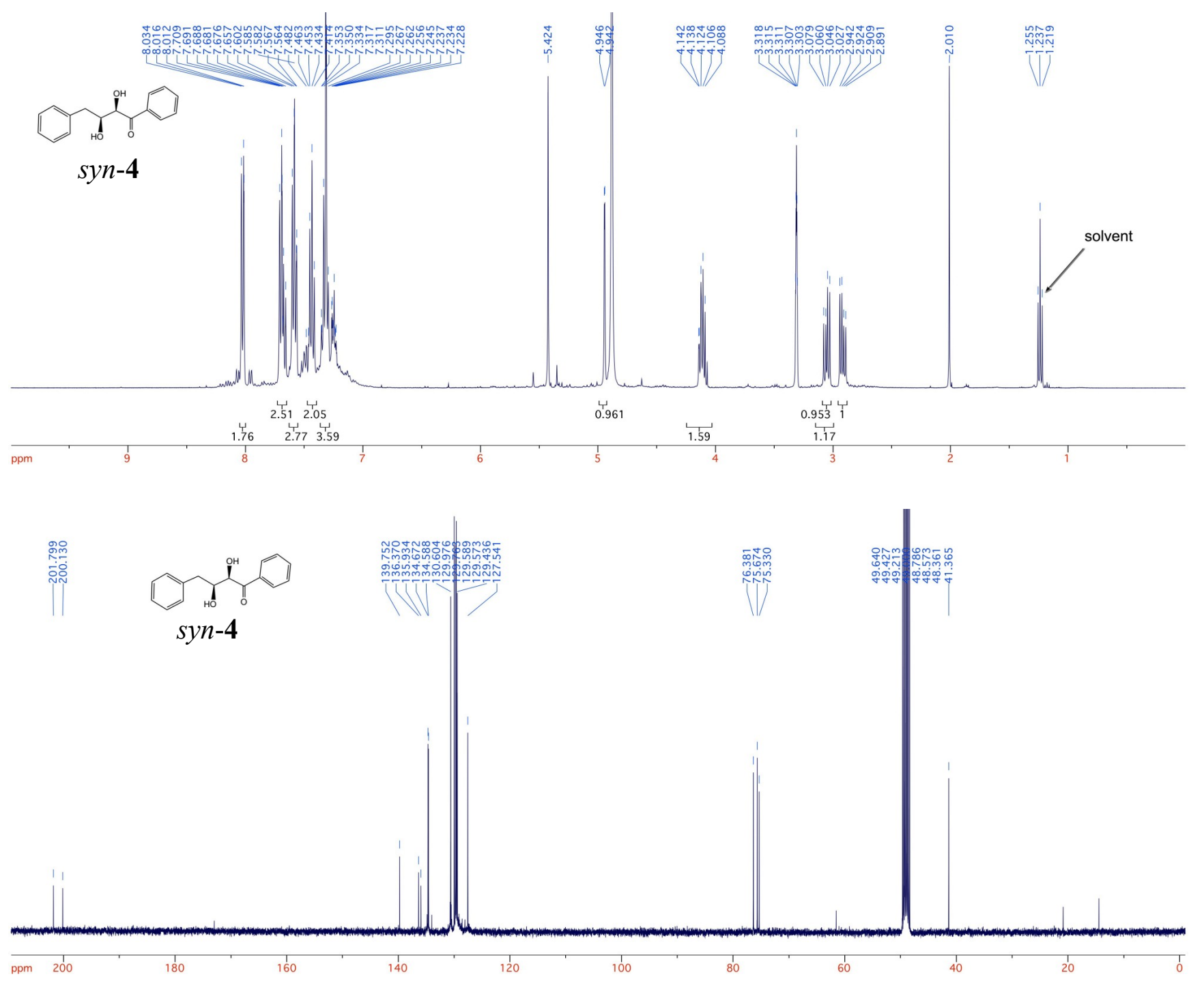


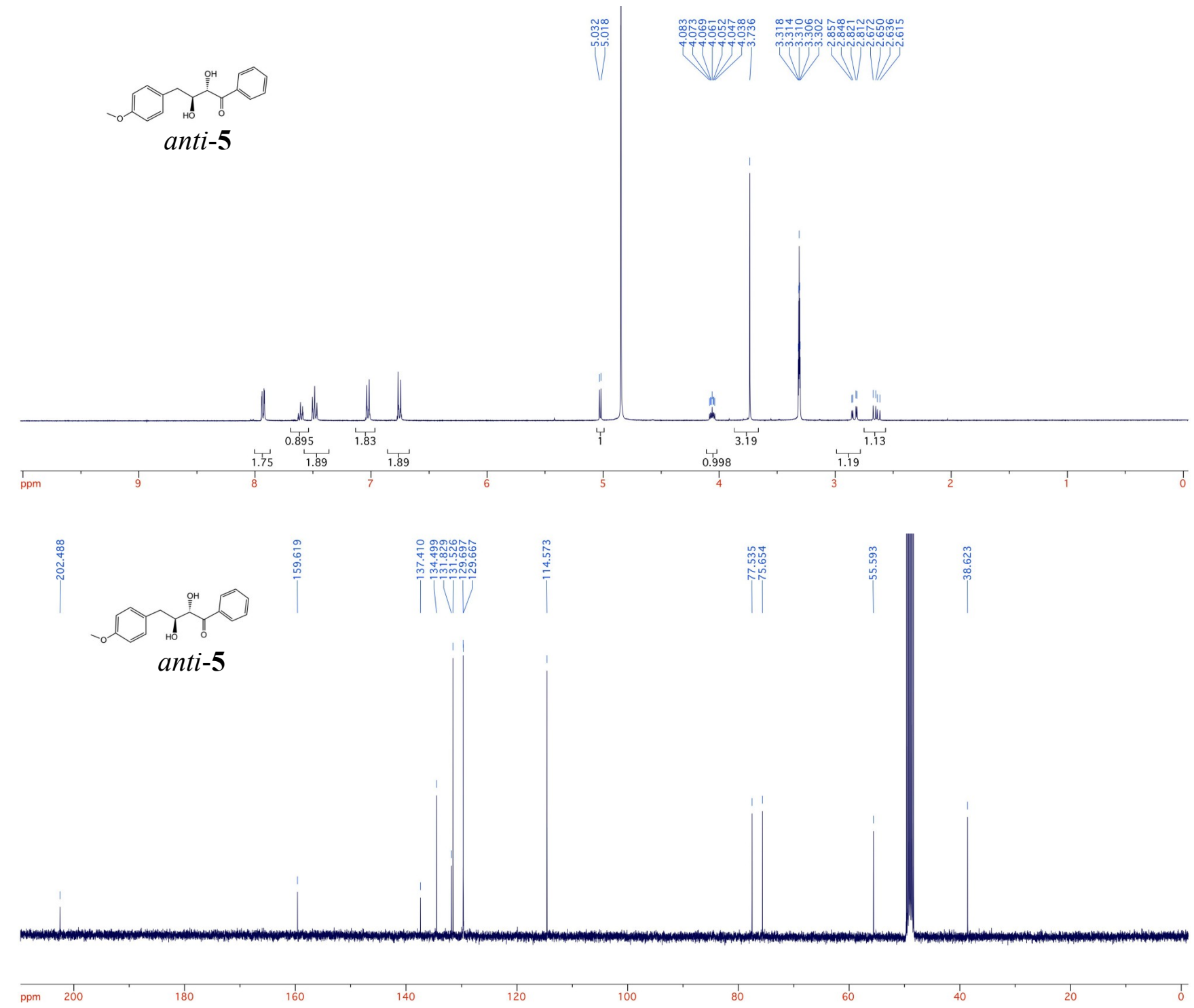



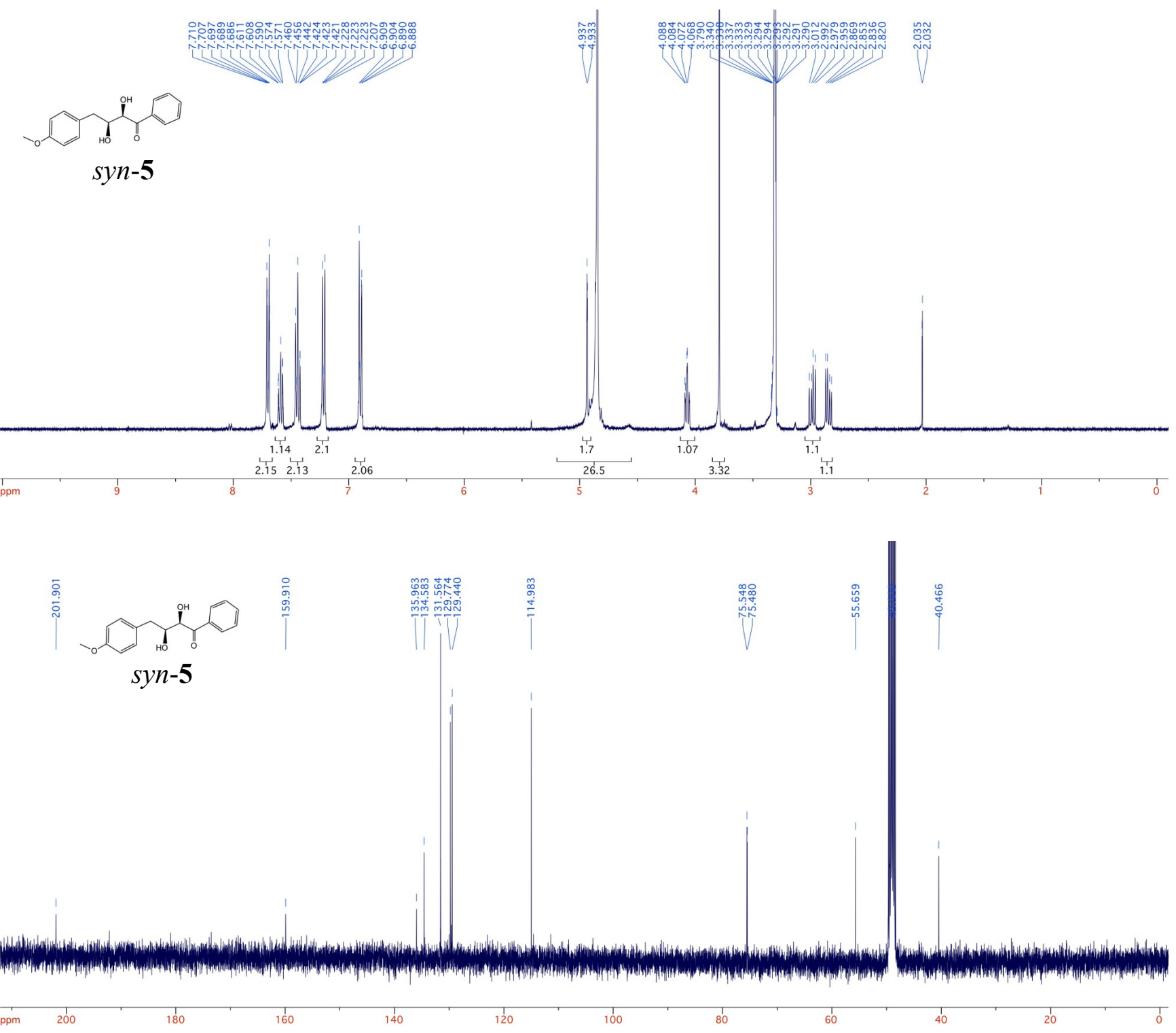


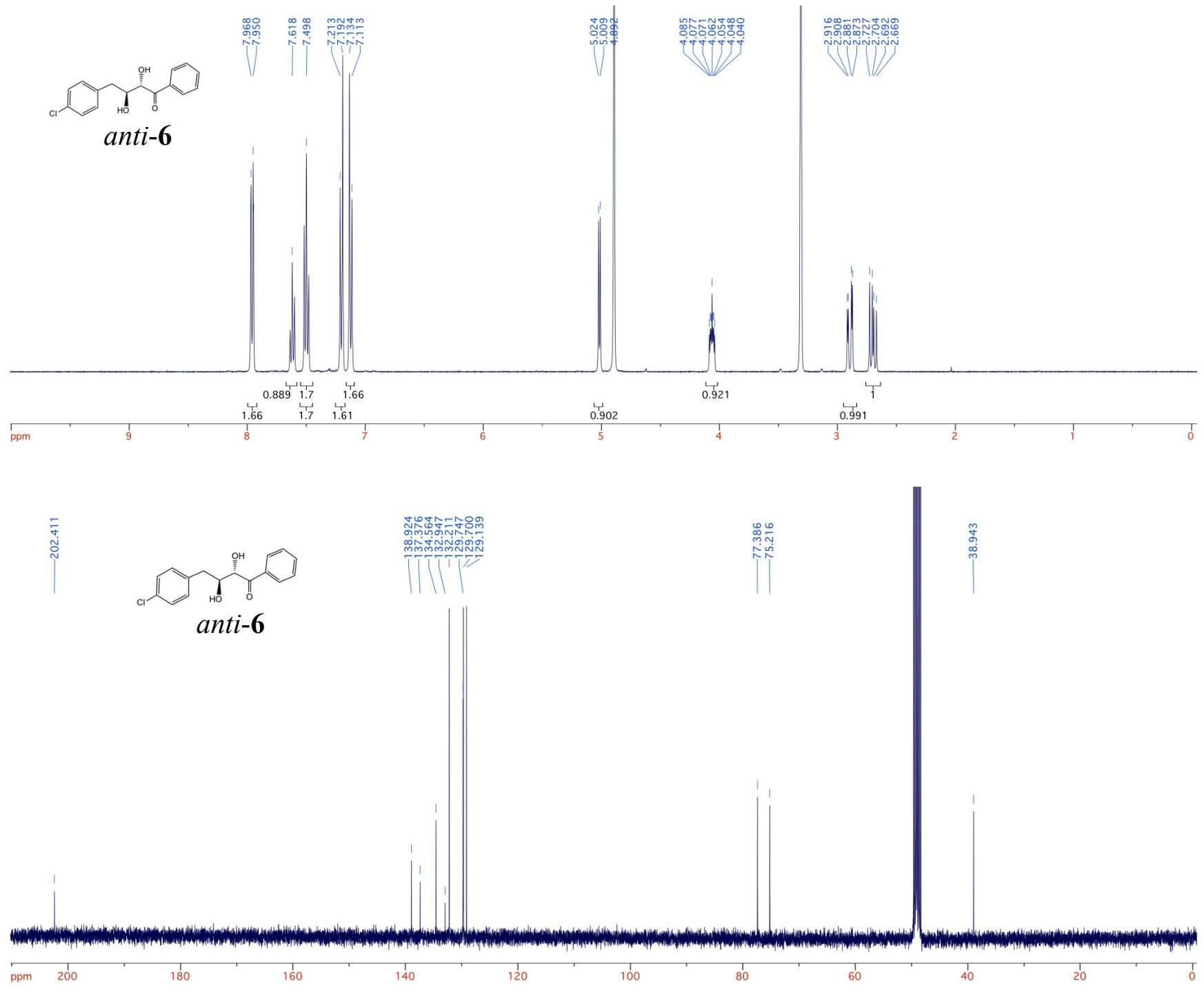




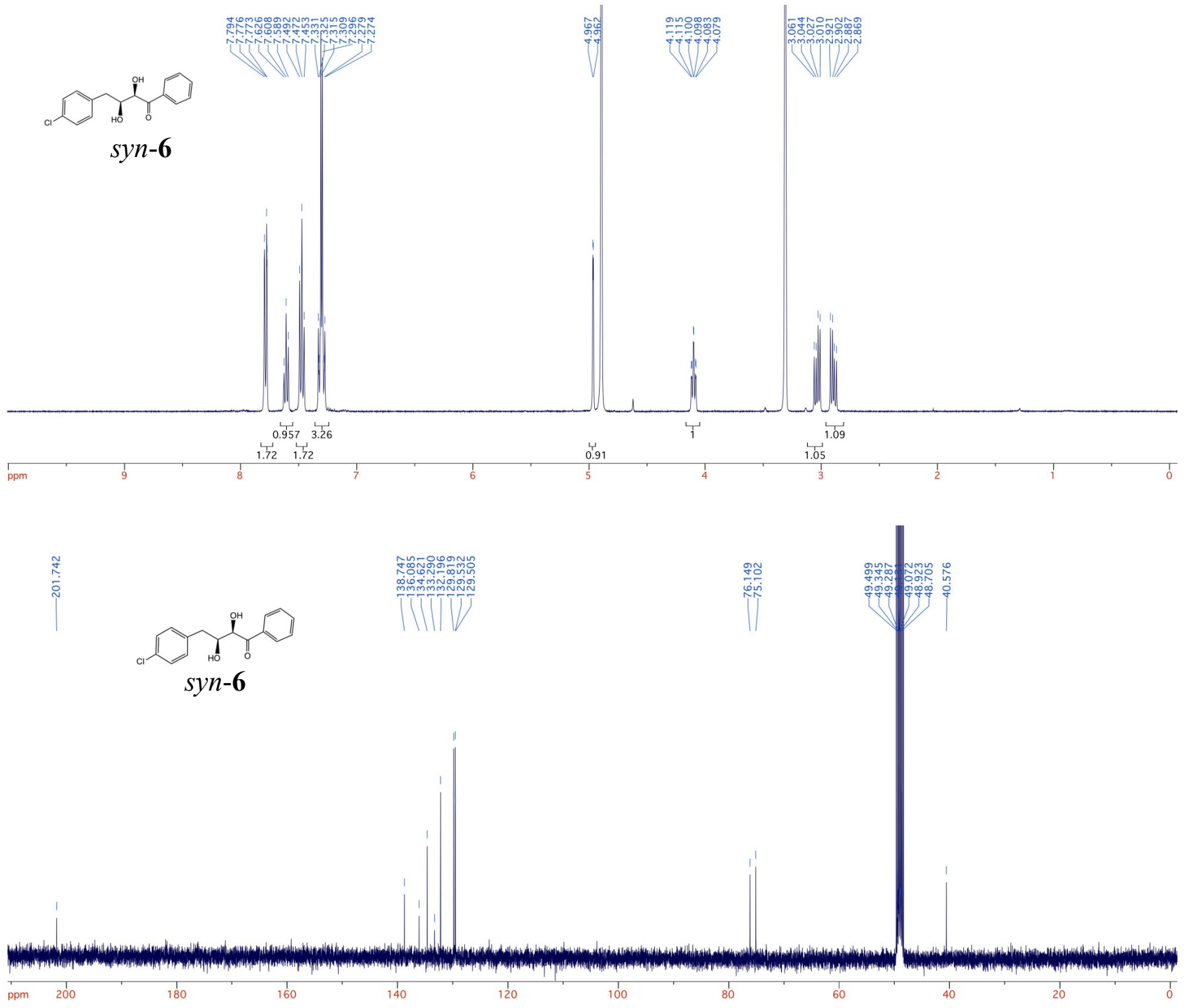




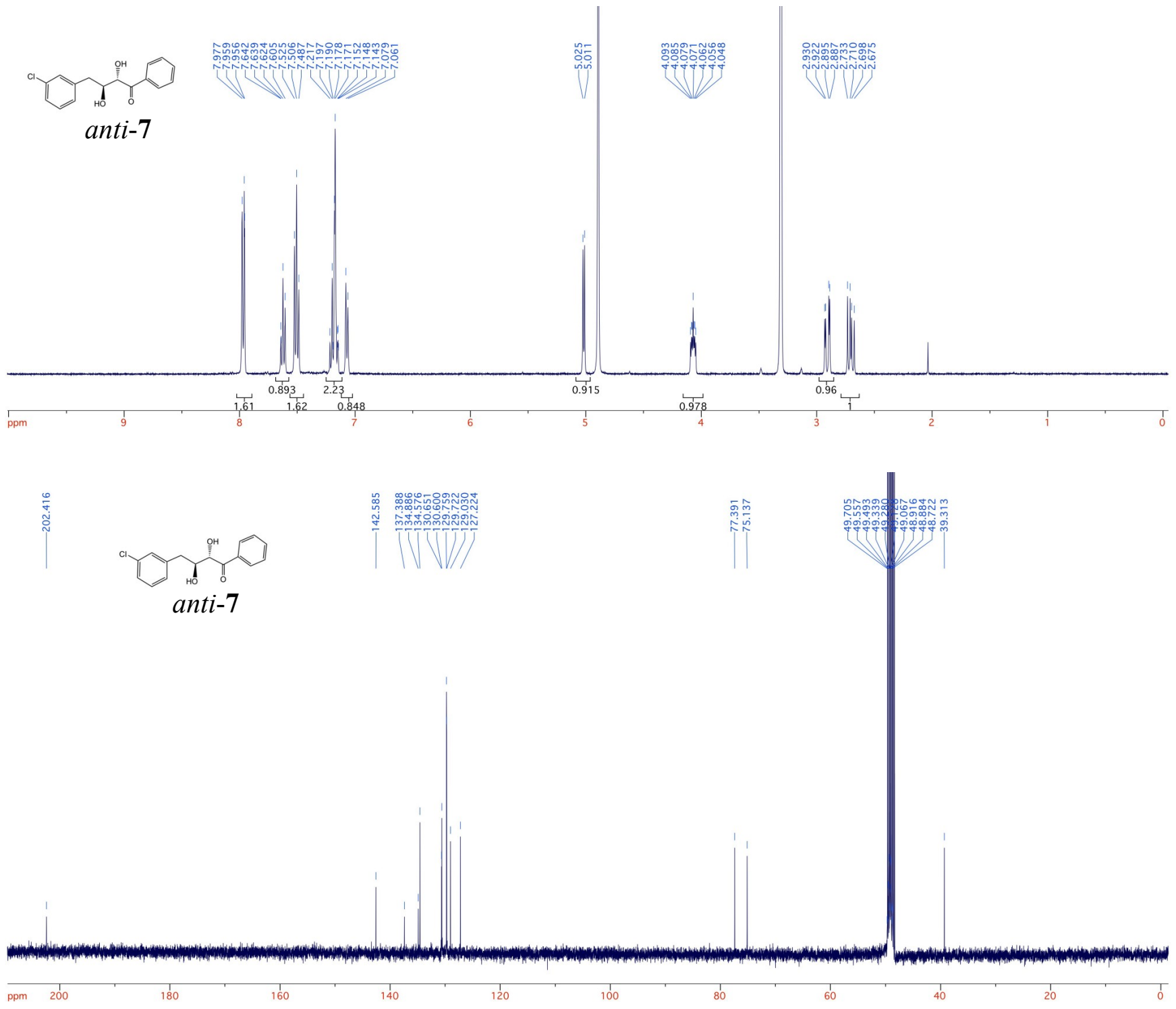




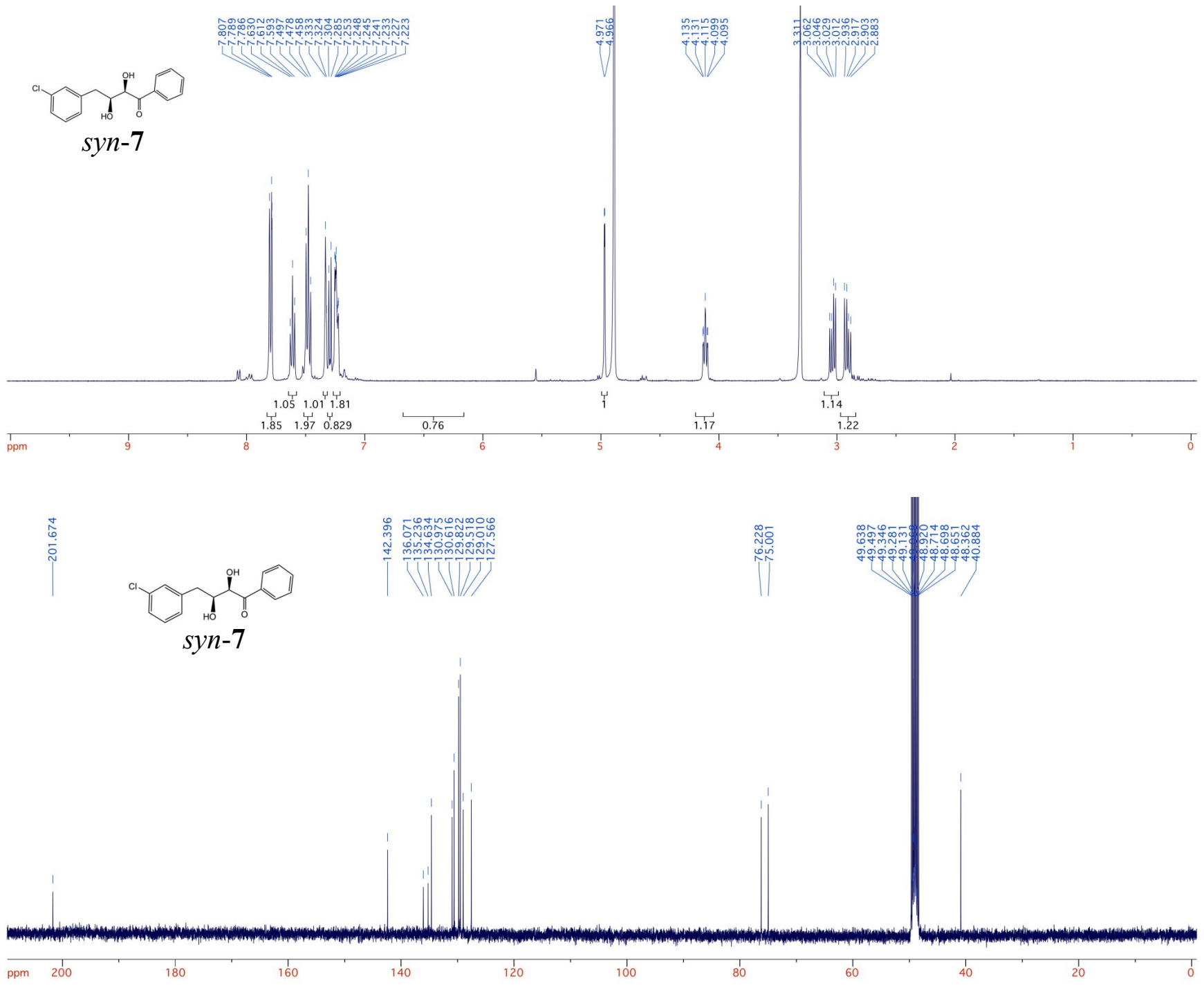




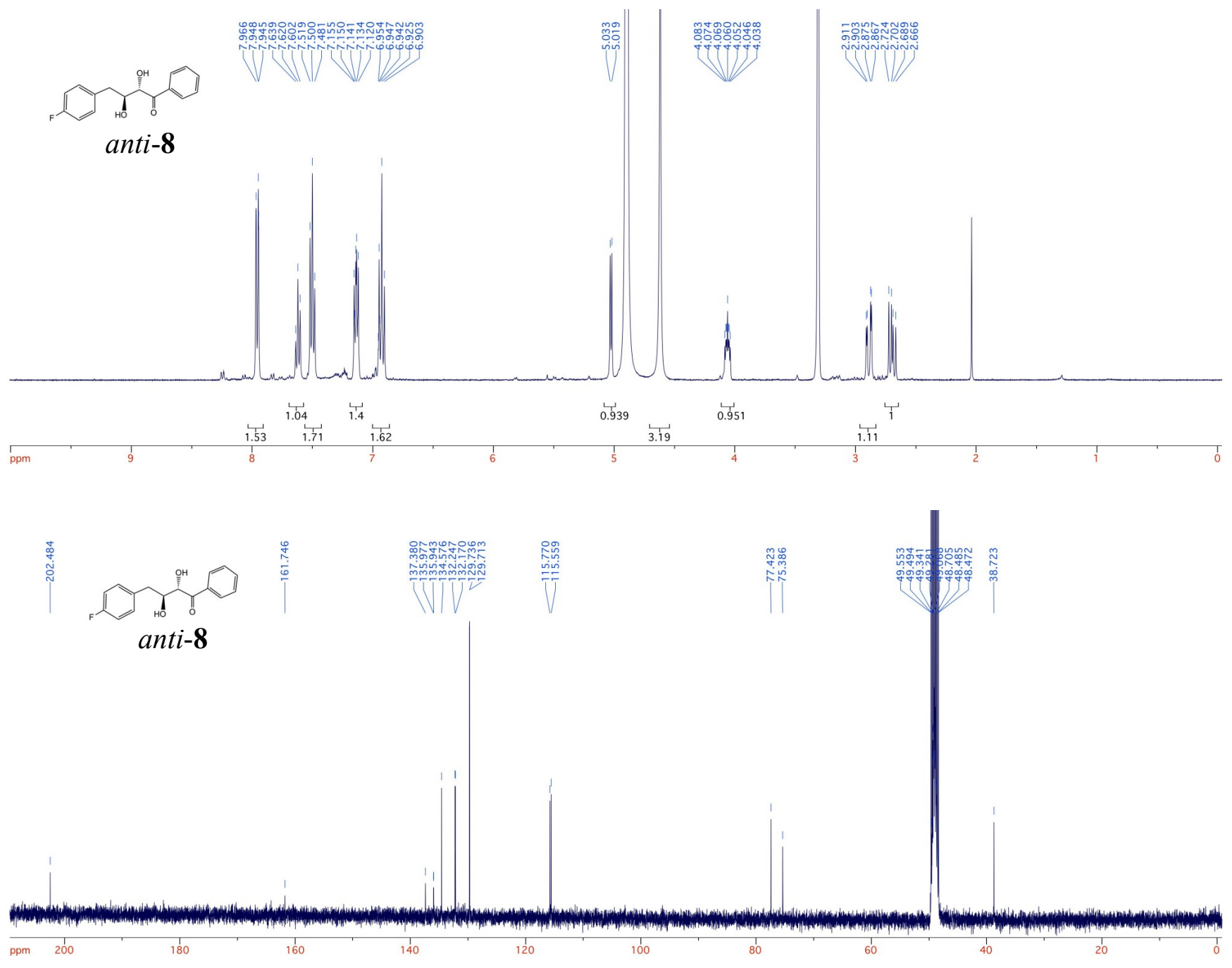




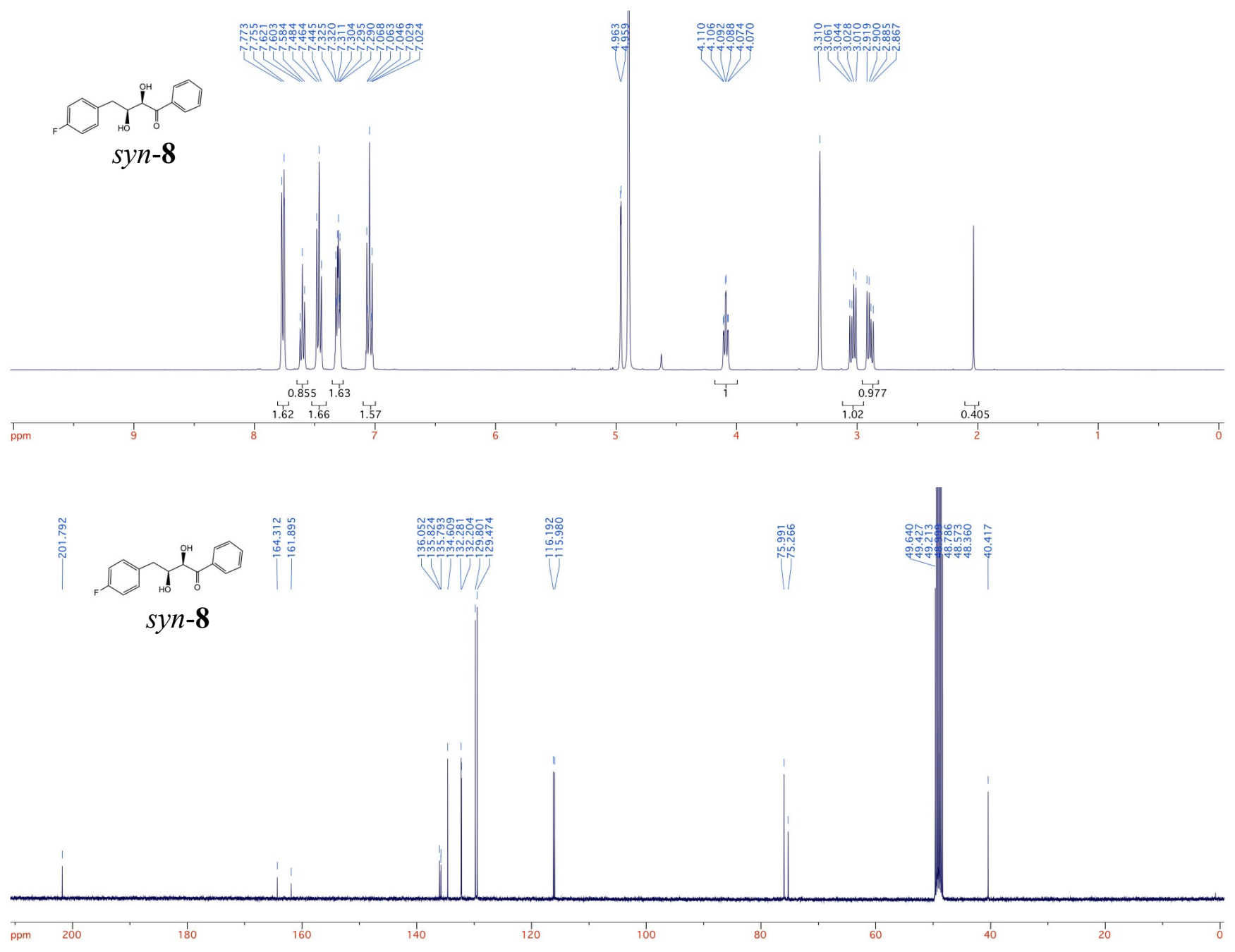




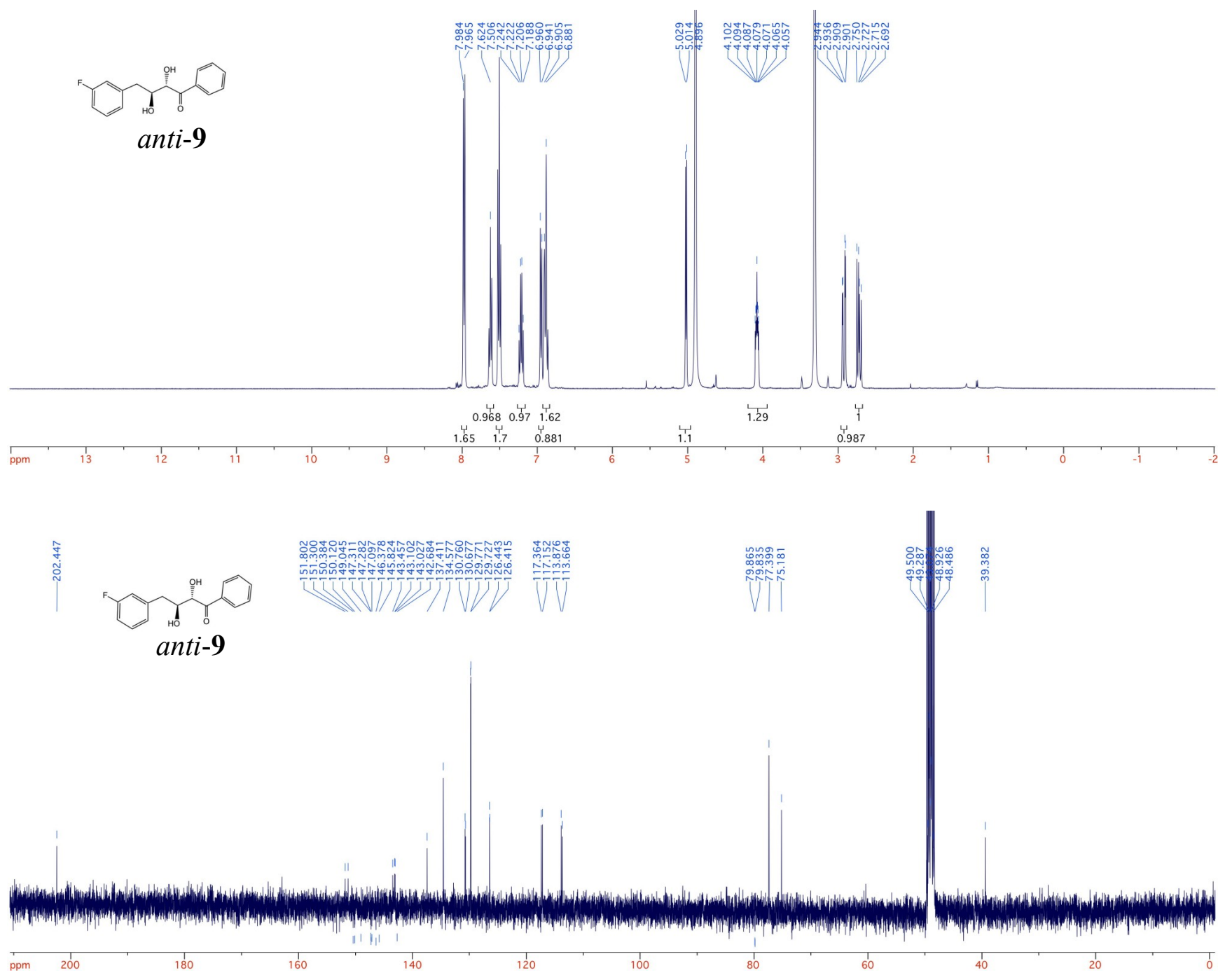




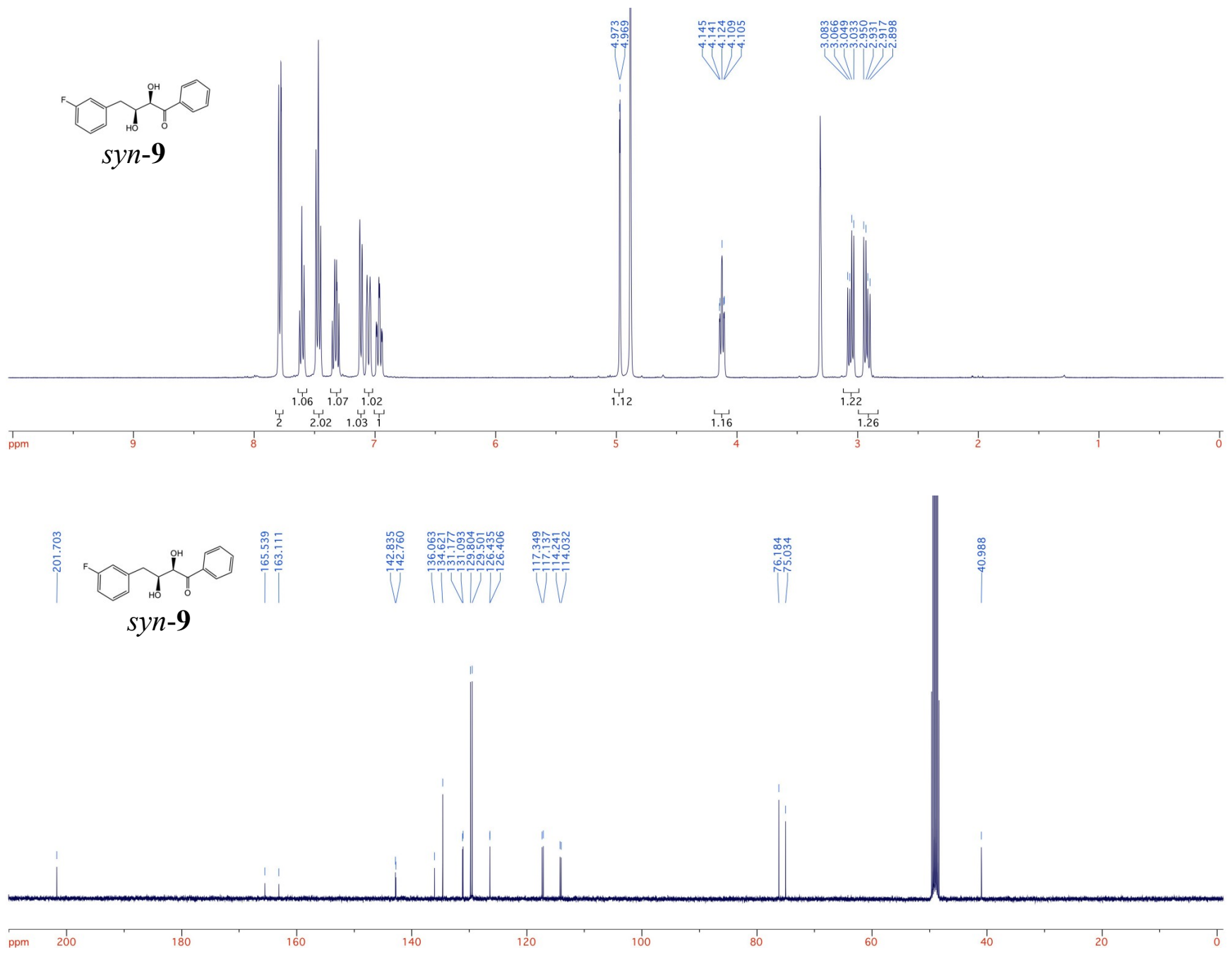



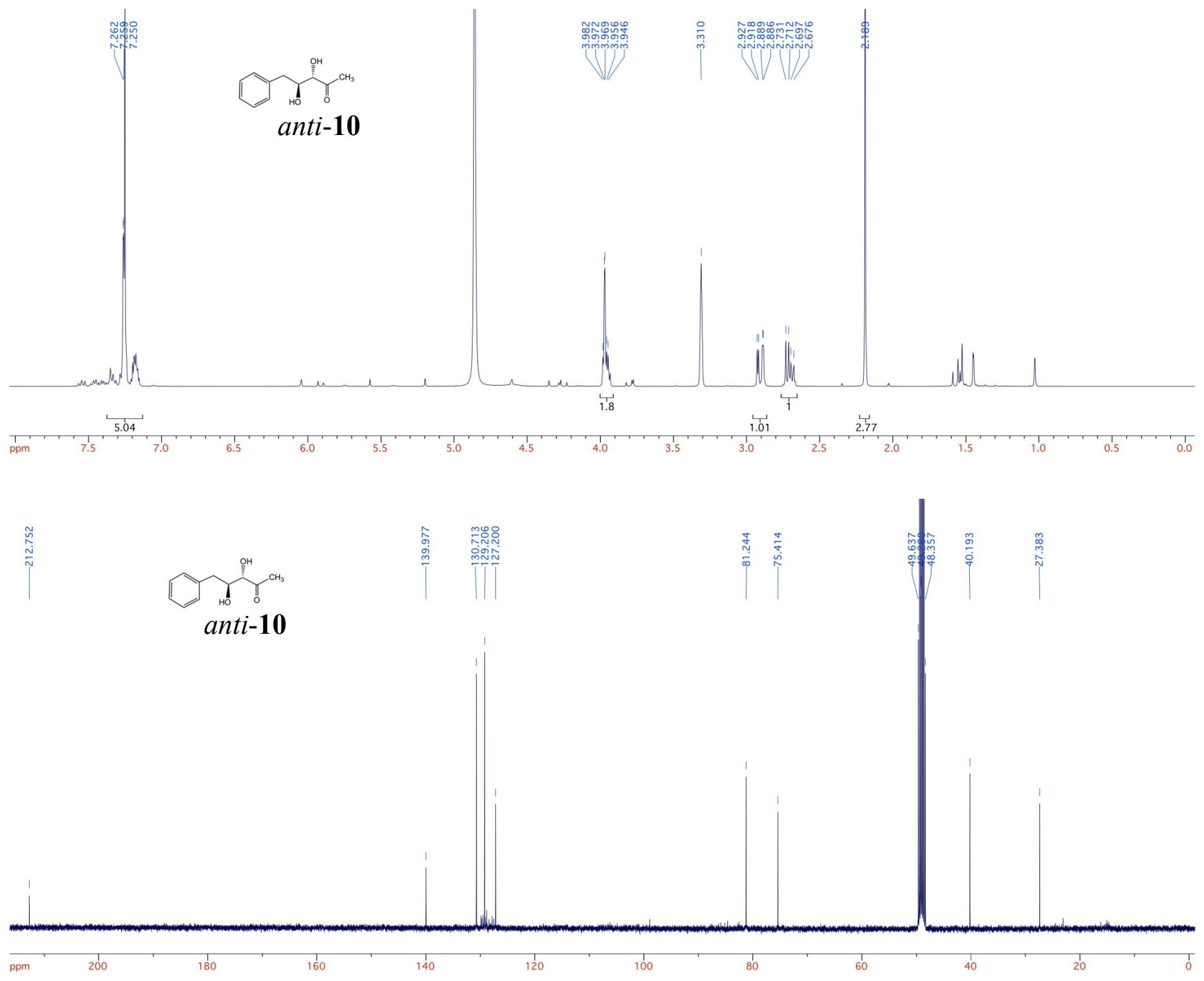

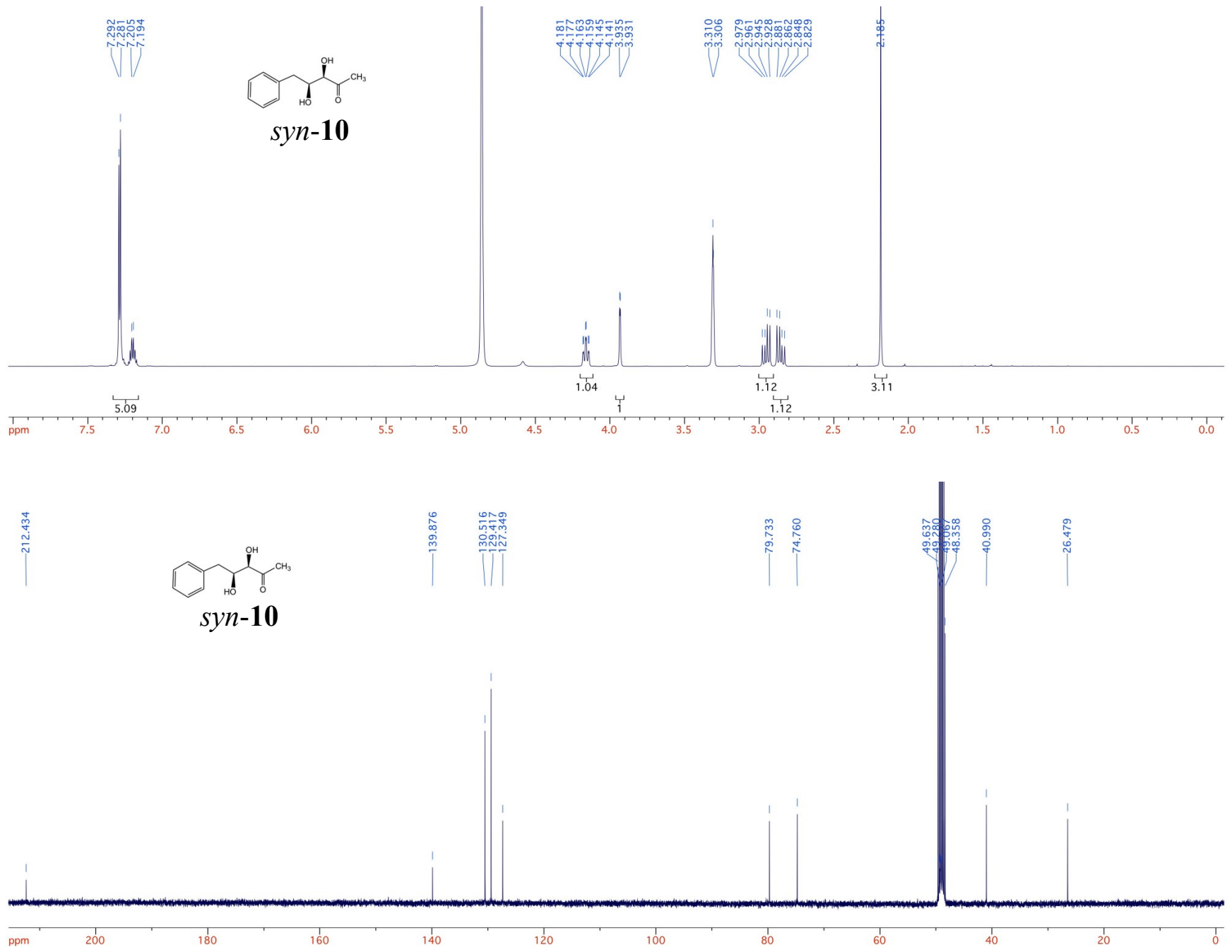


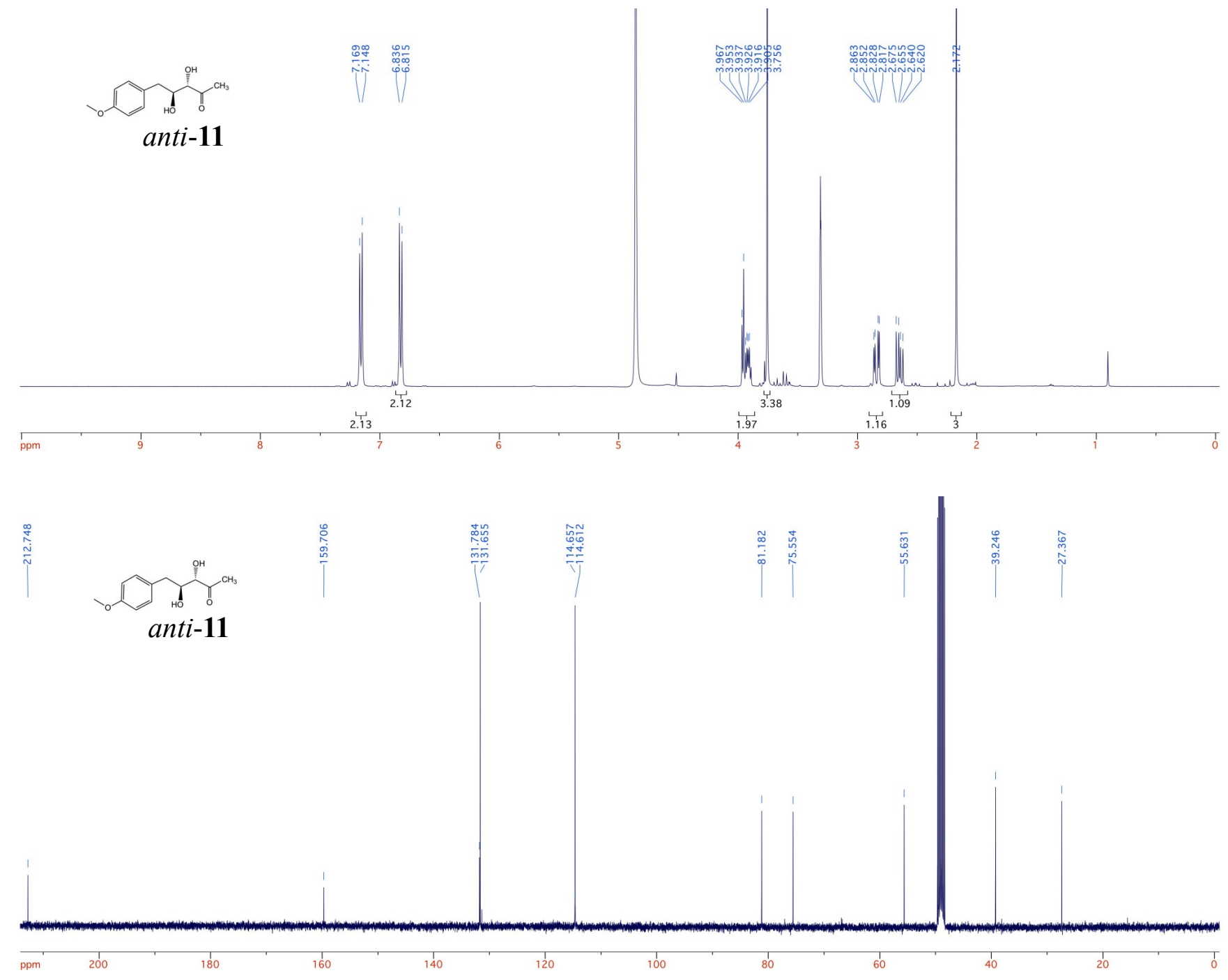




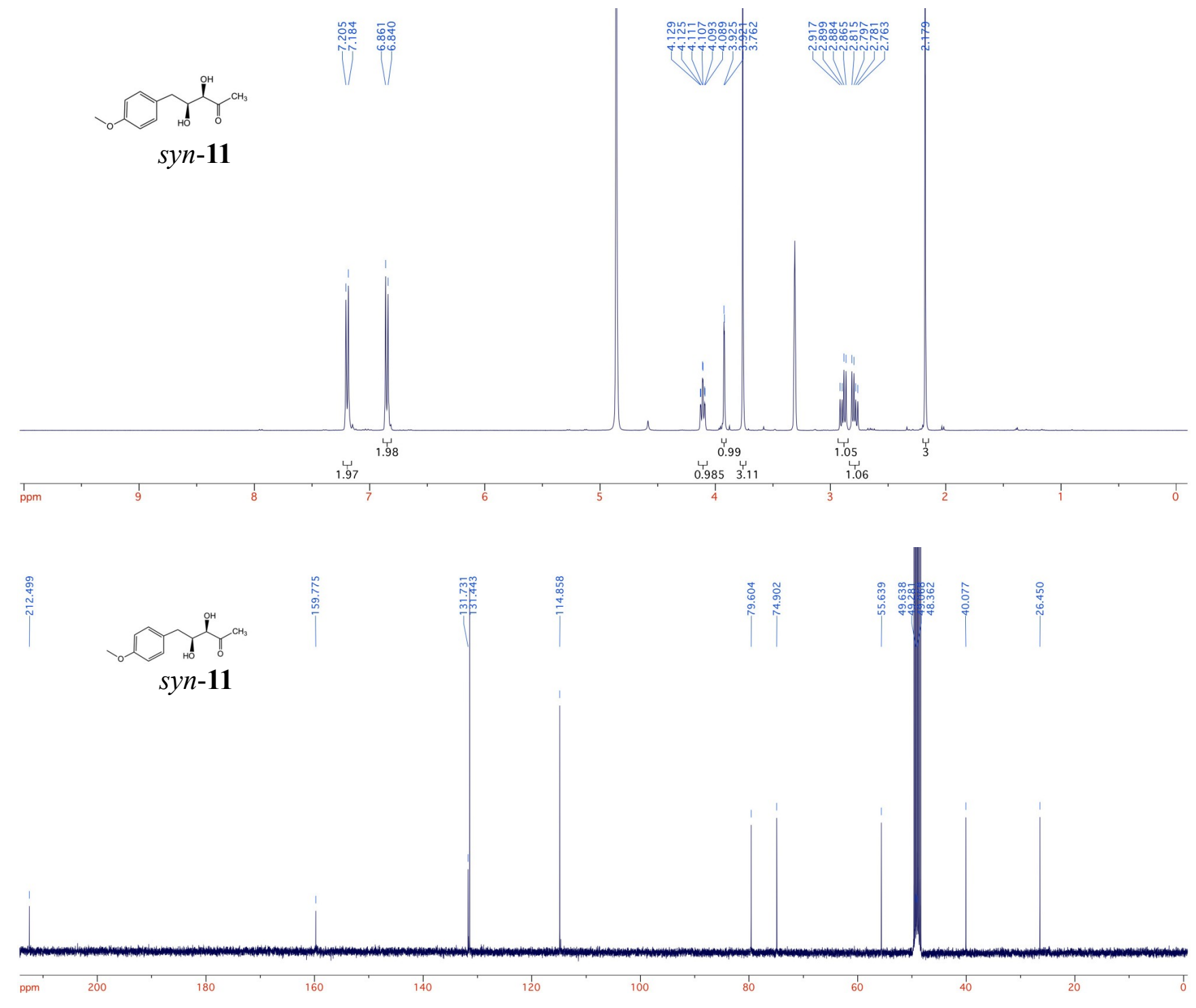




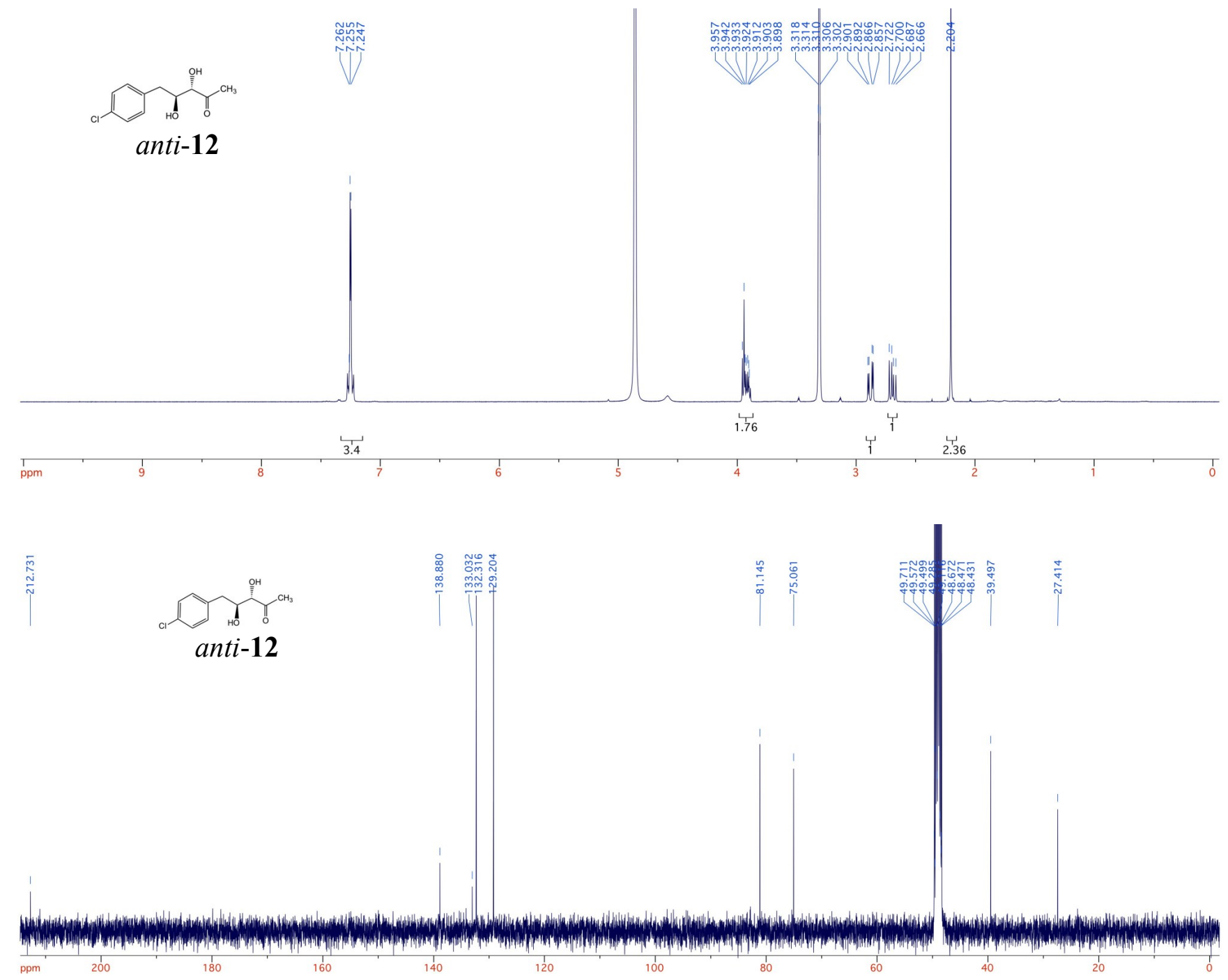




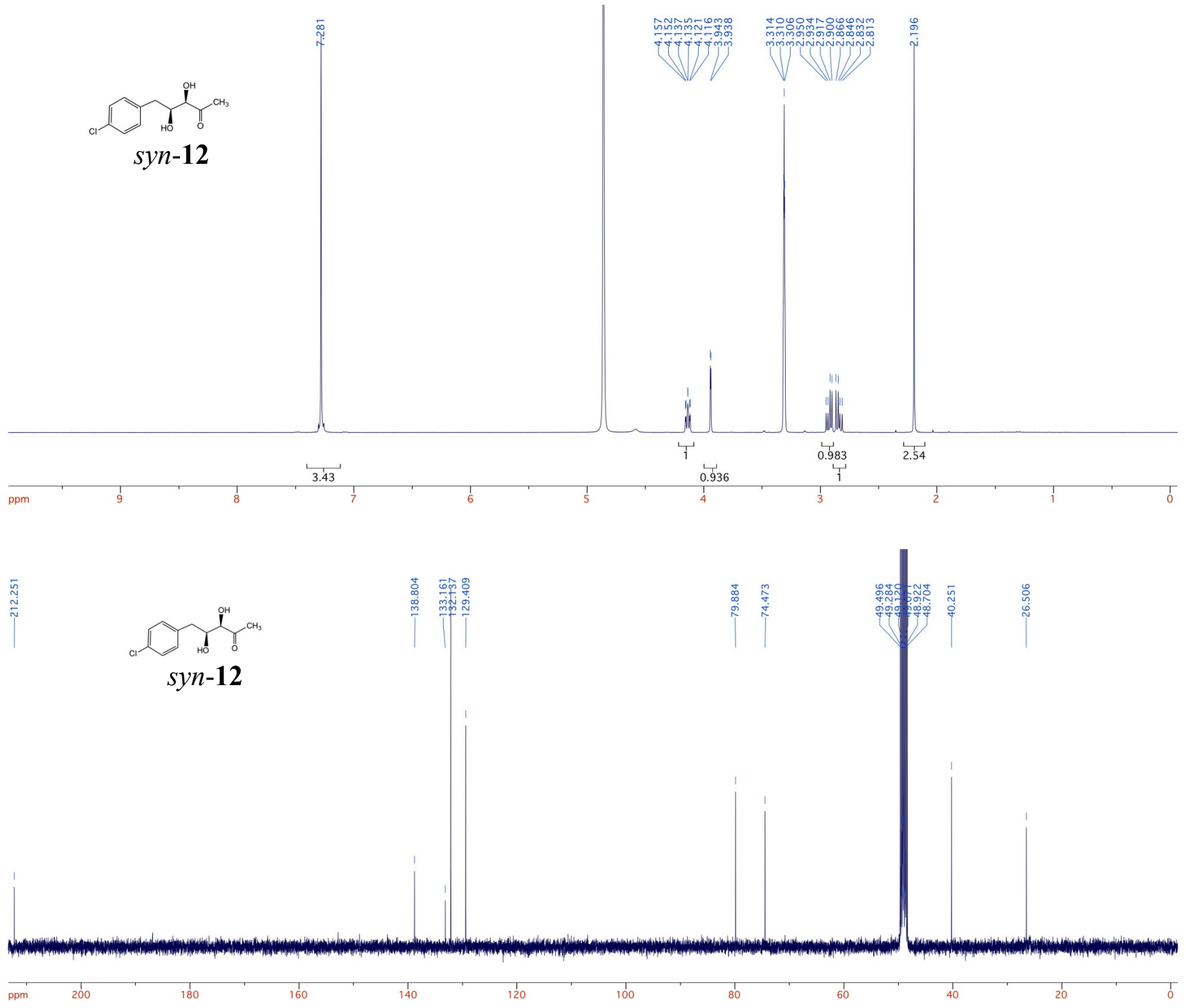




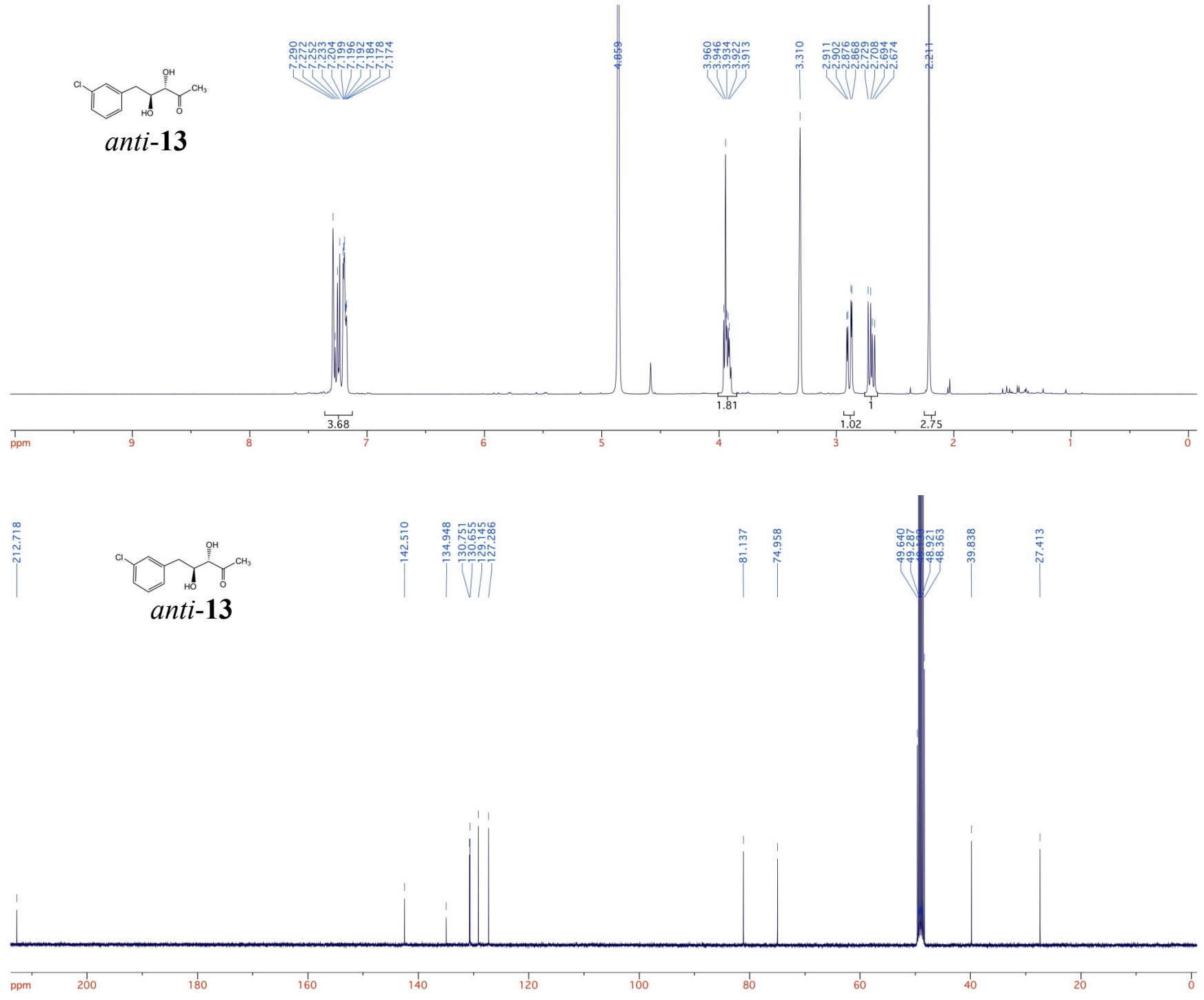




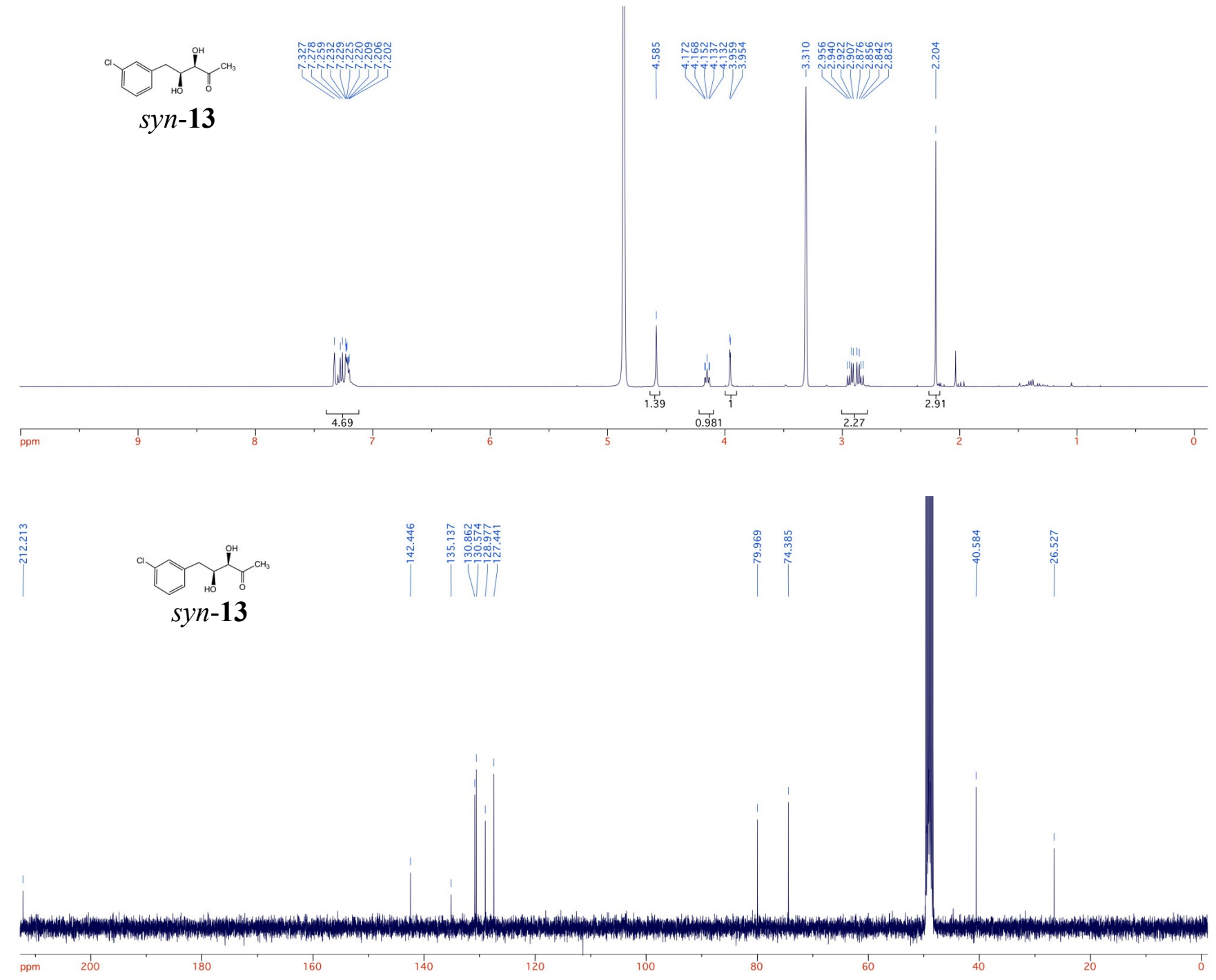




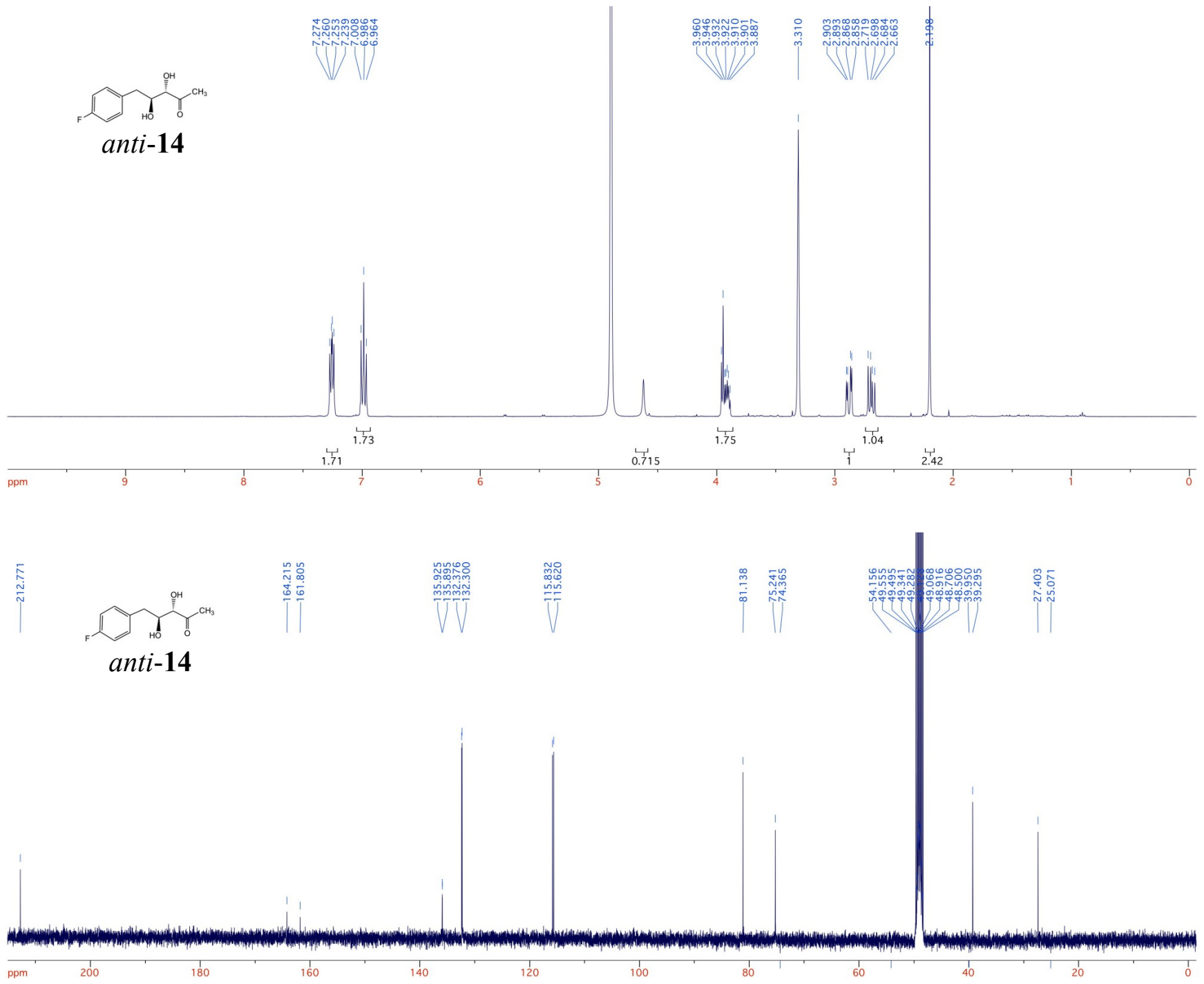




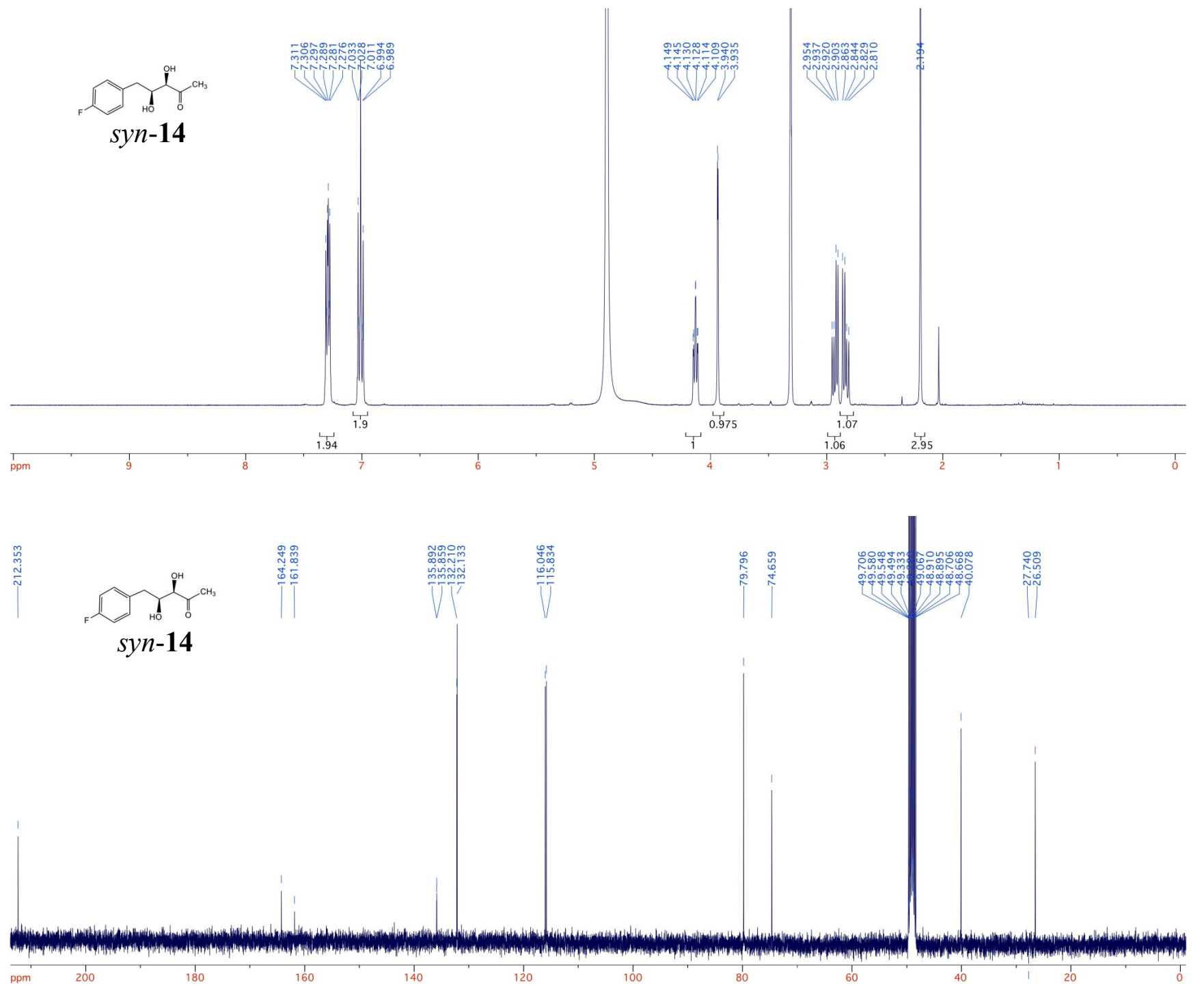




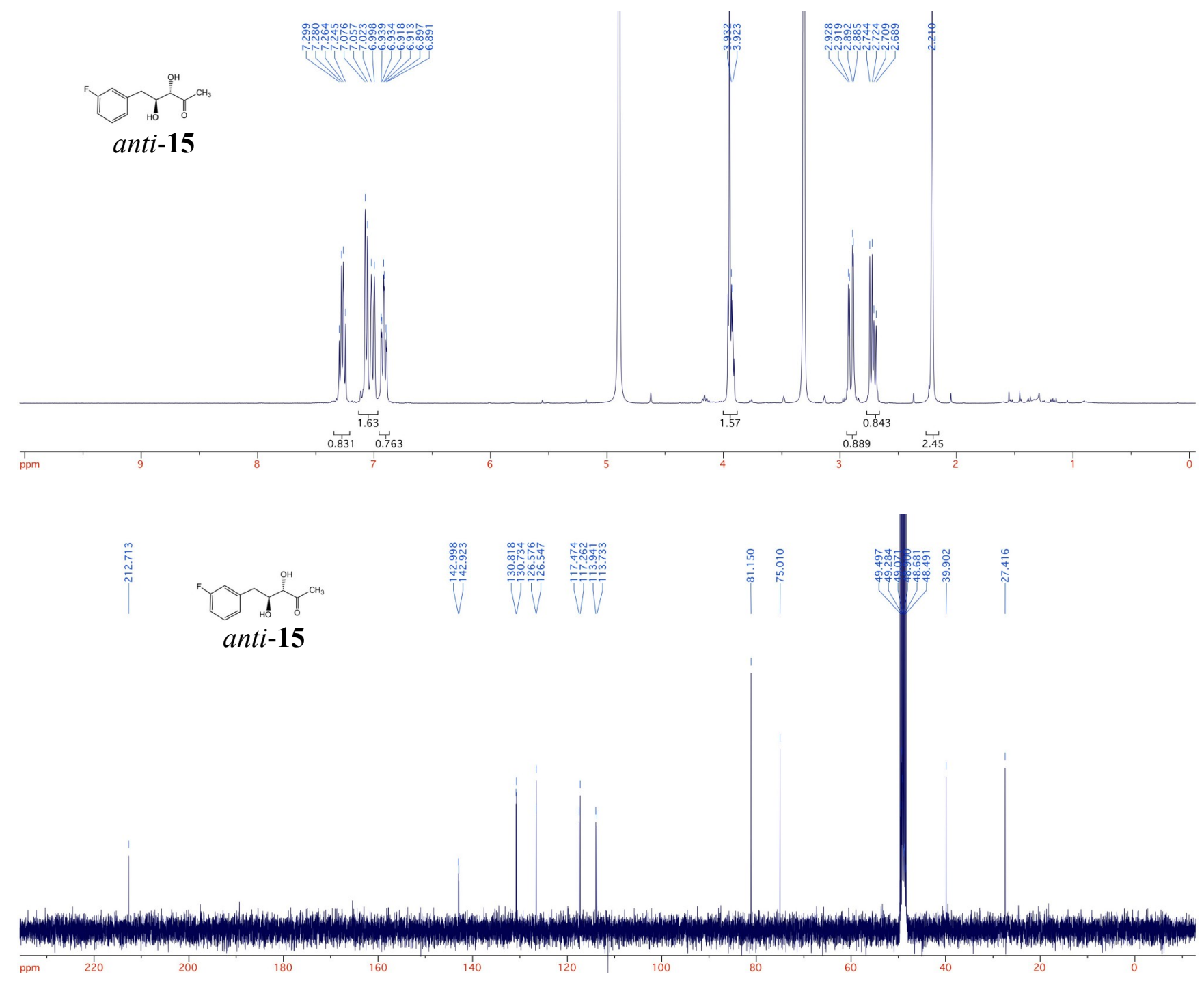




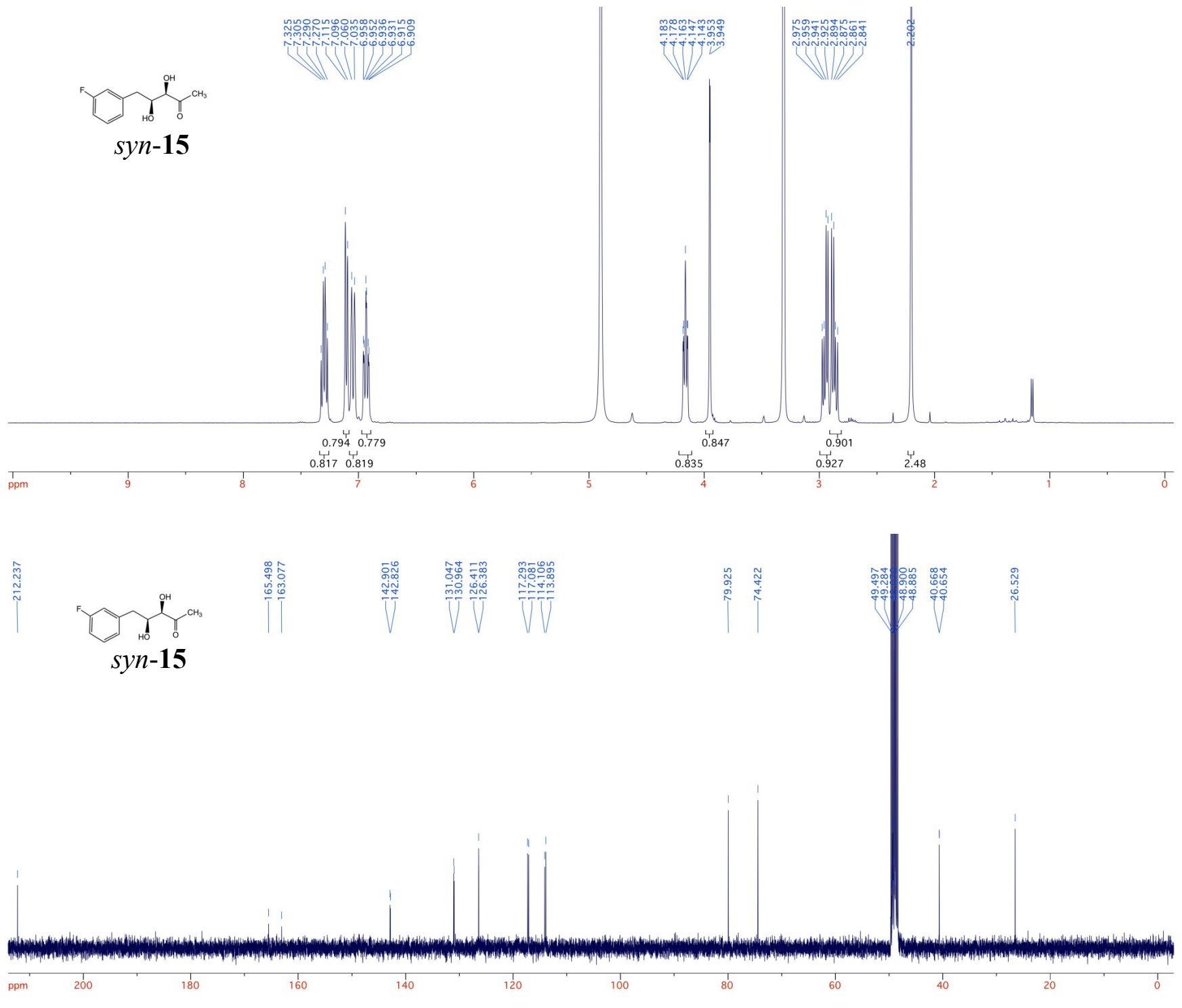



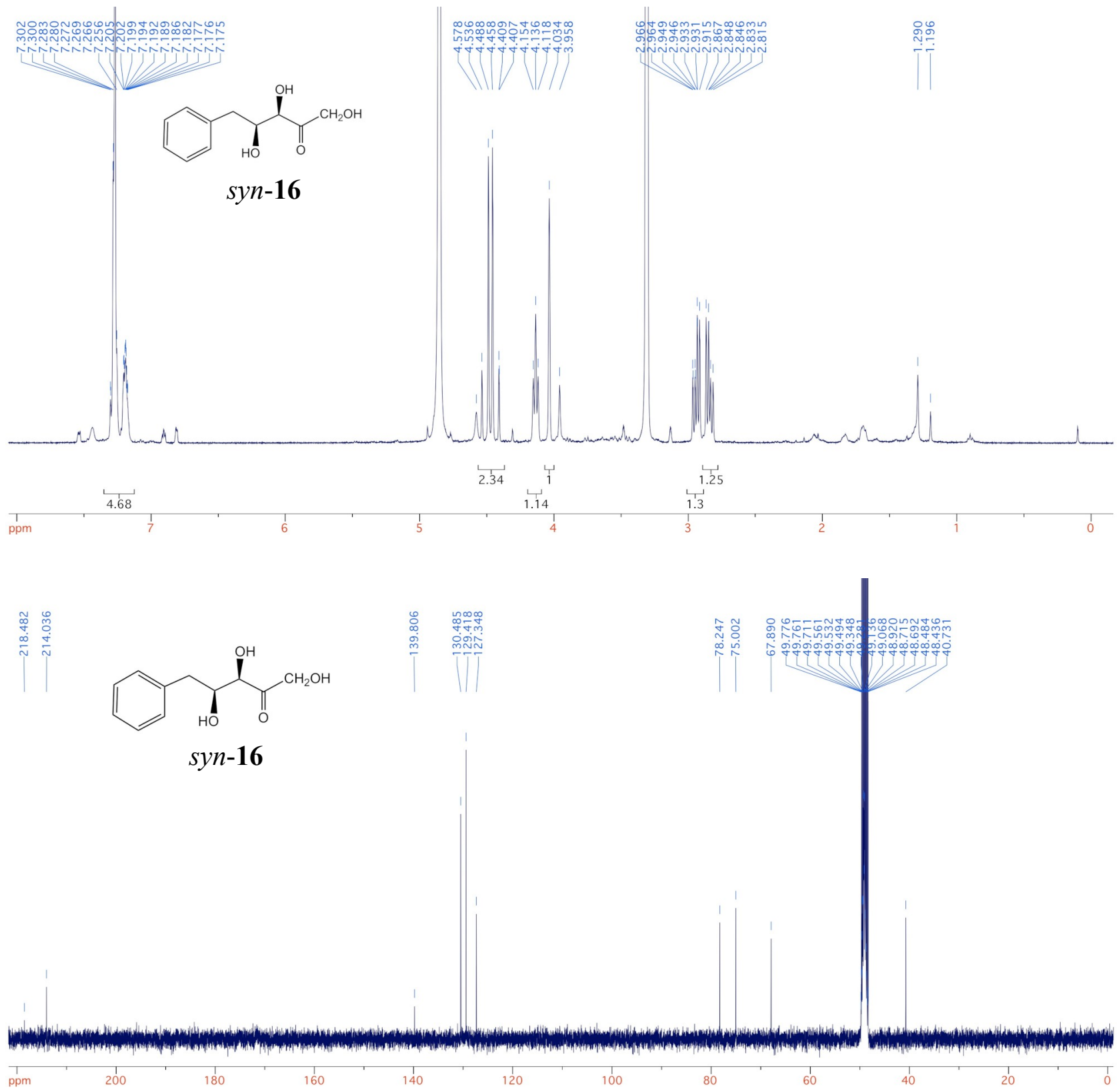

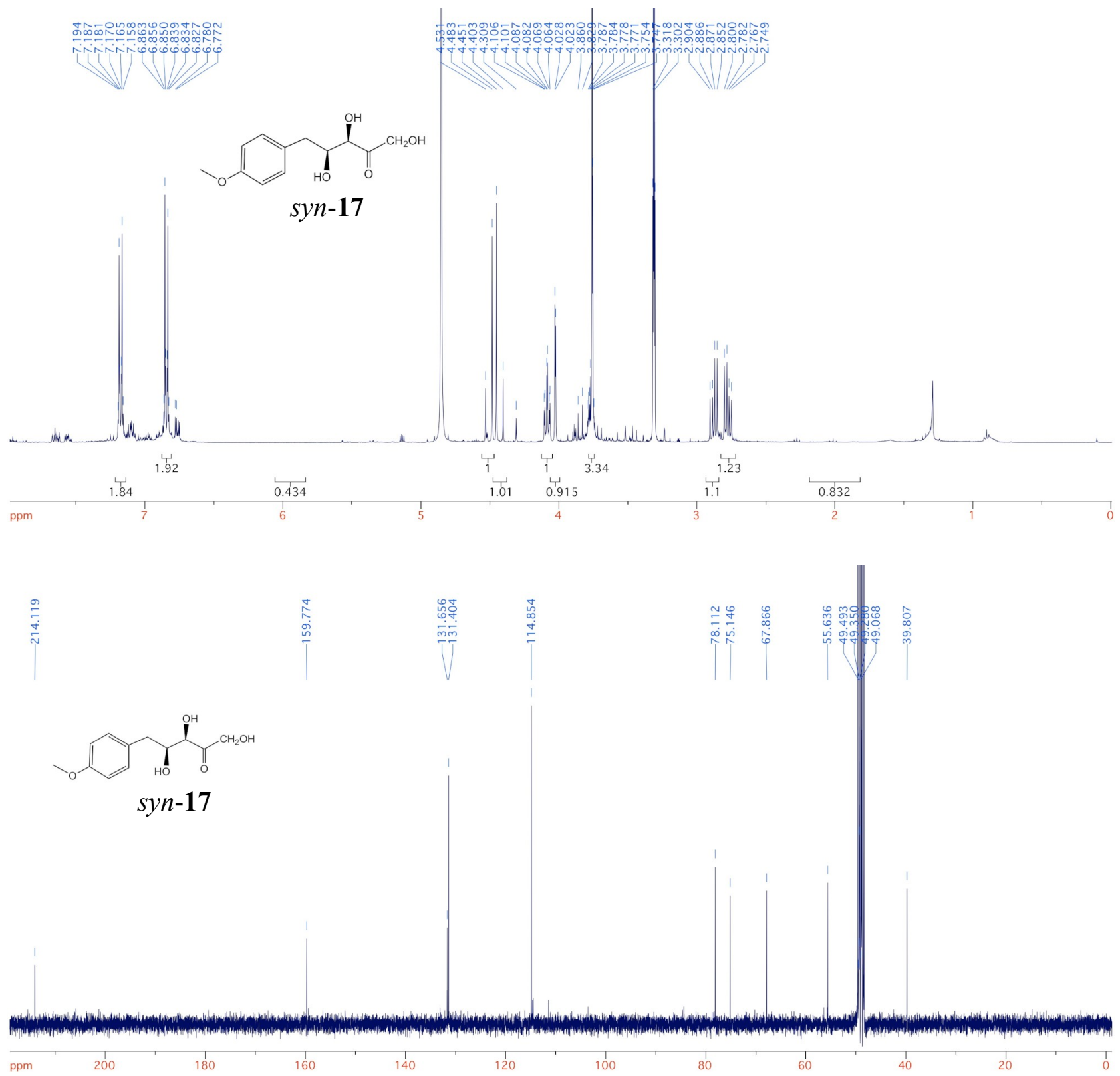


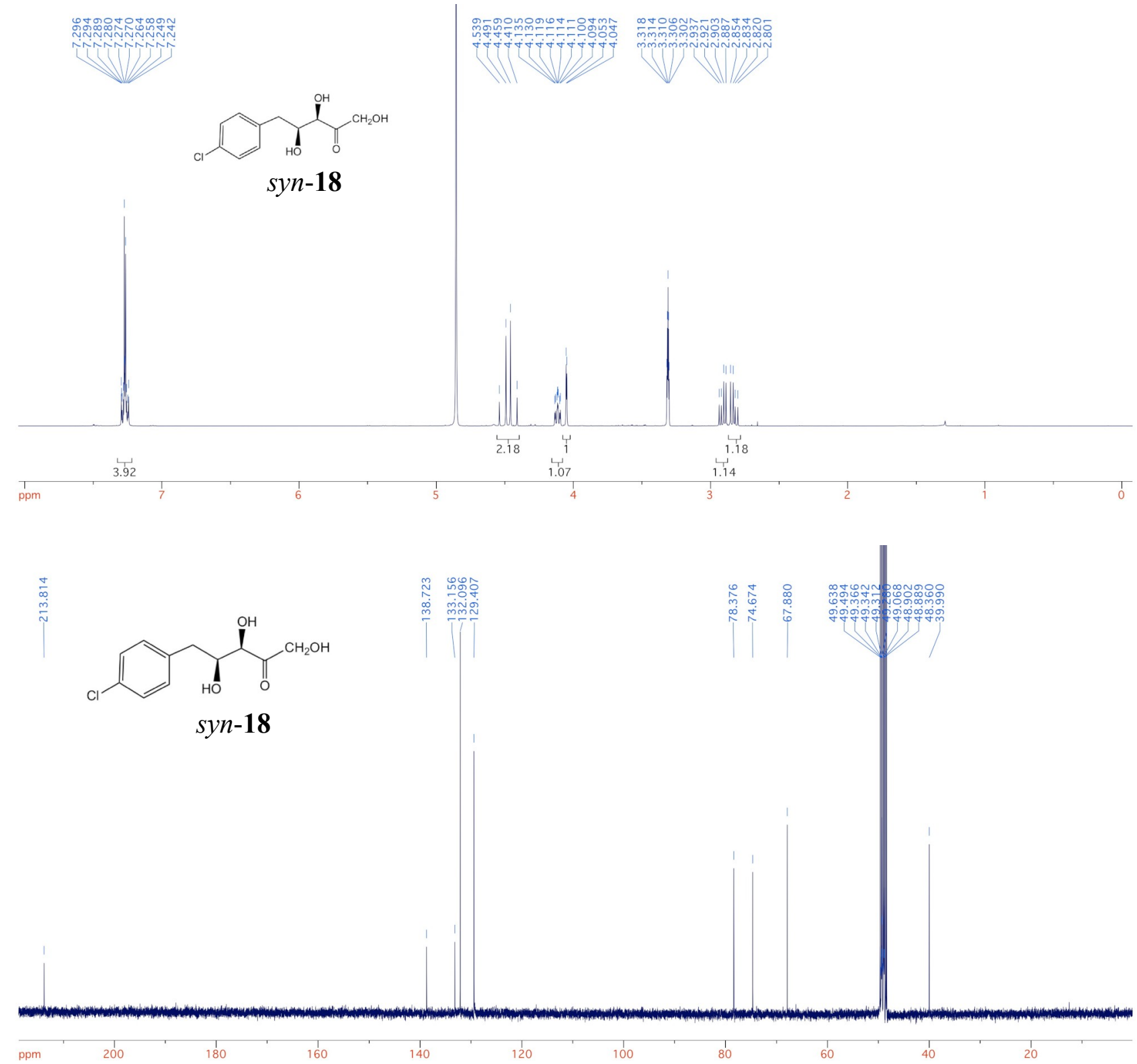




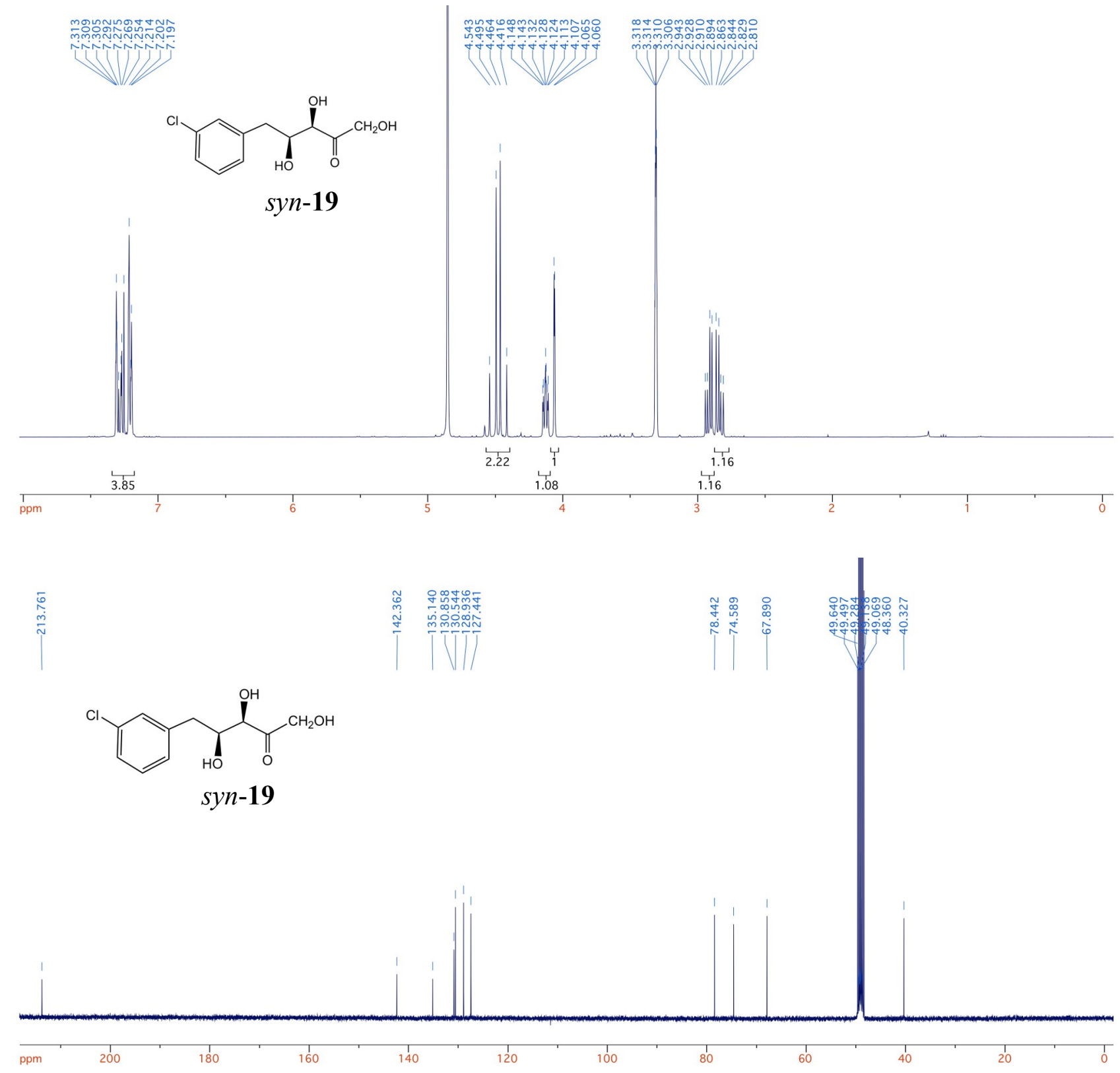




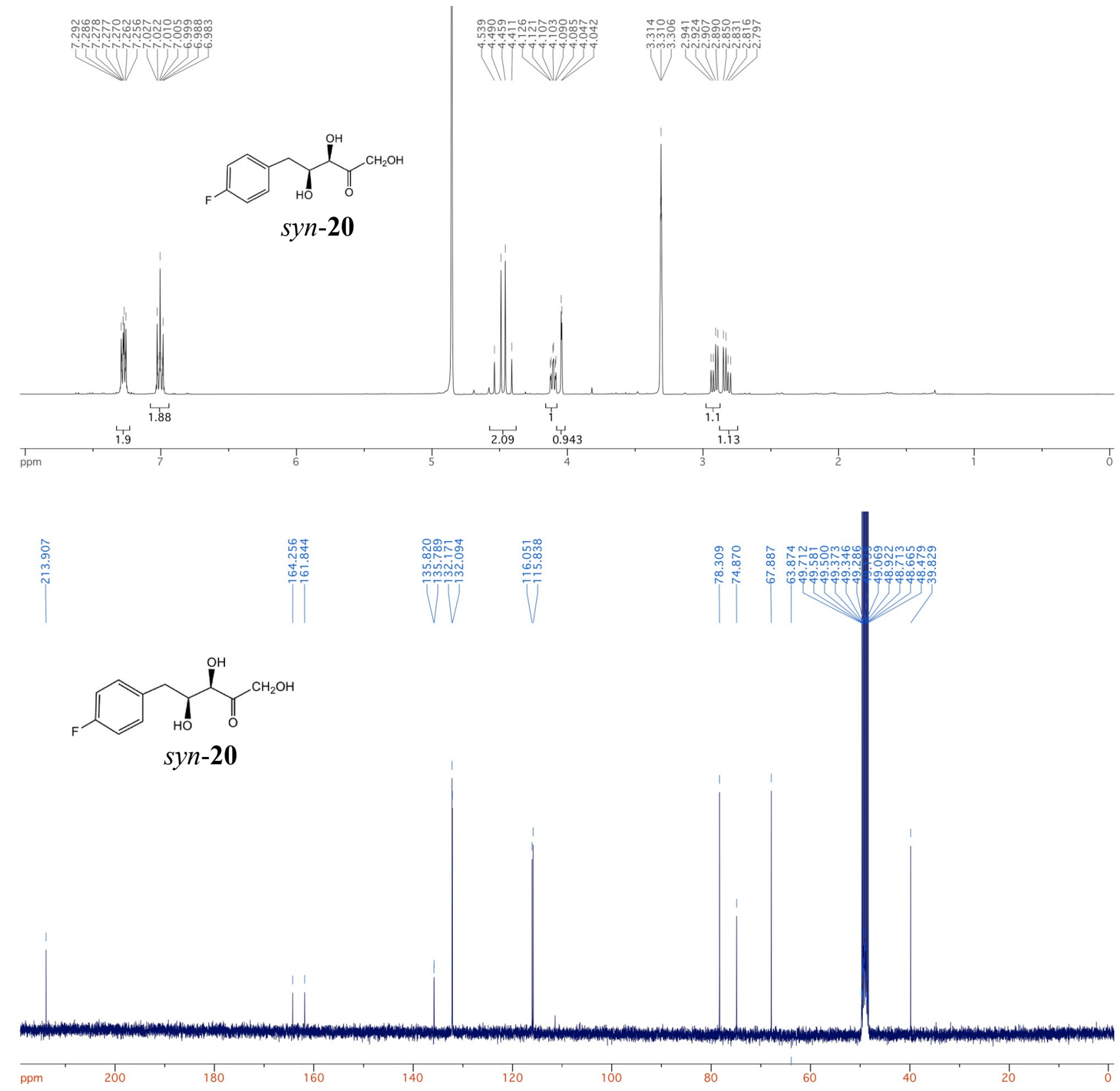



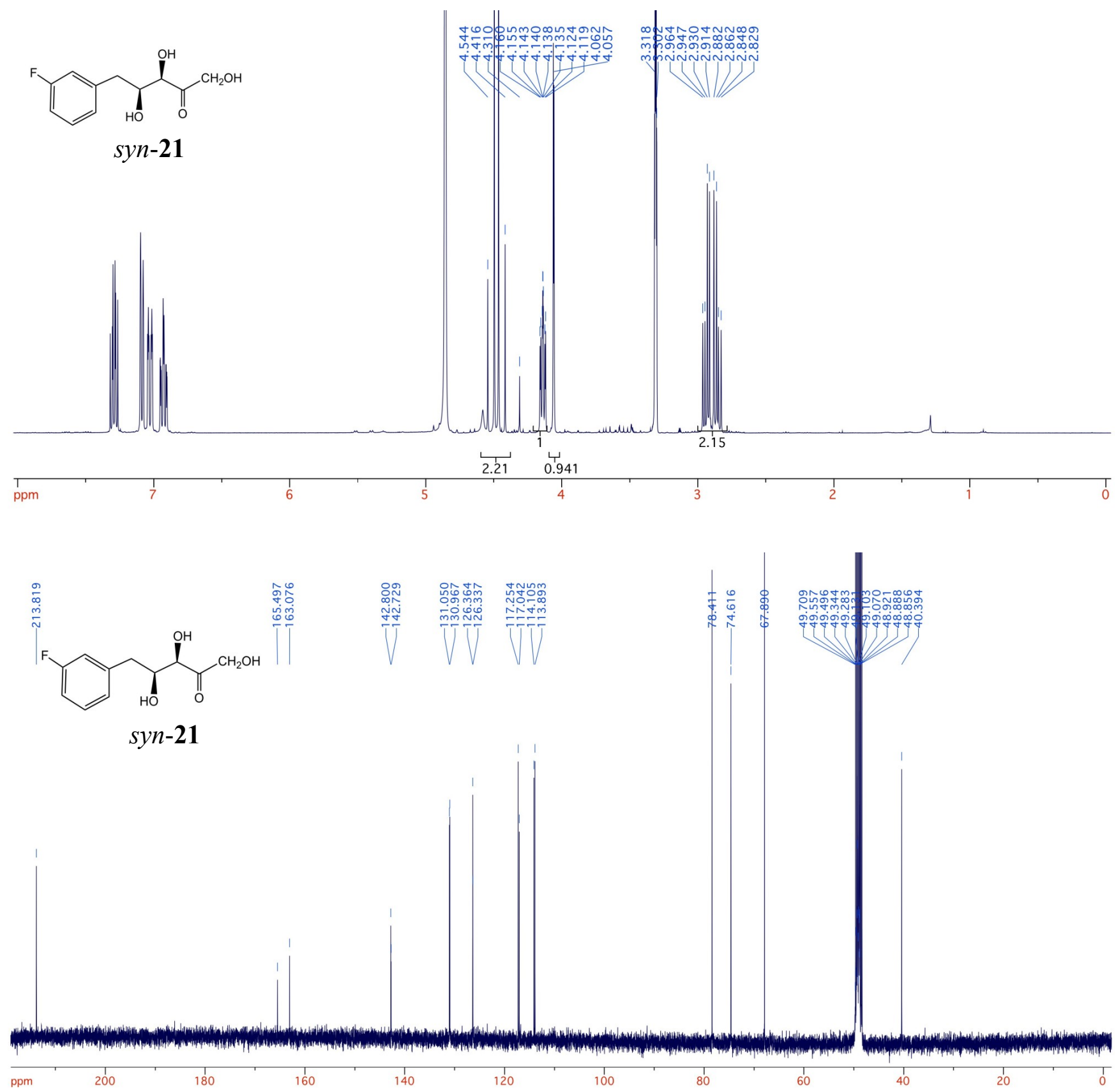

Figure S3. ${ }^{1} \mathrm{H}$ - and ${ }^{13} \mathrm{C}-\mathrm{NMR}$ spectra of new (5-9, 11-15, 18-21) and reference (4, 10 and 16) compounds. 
(a)

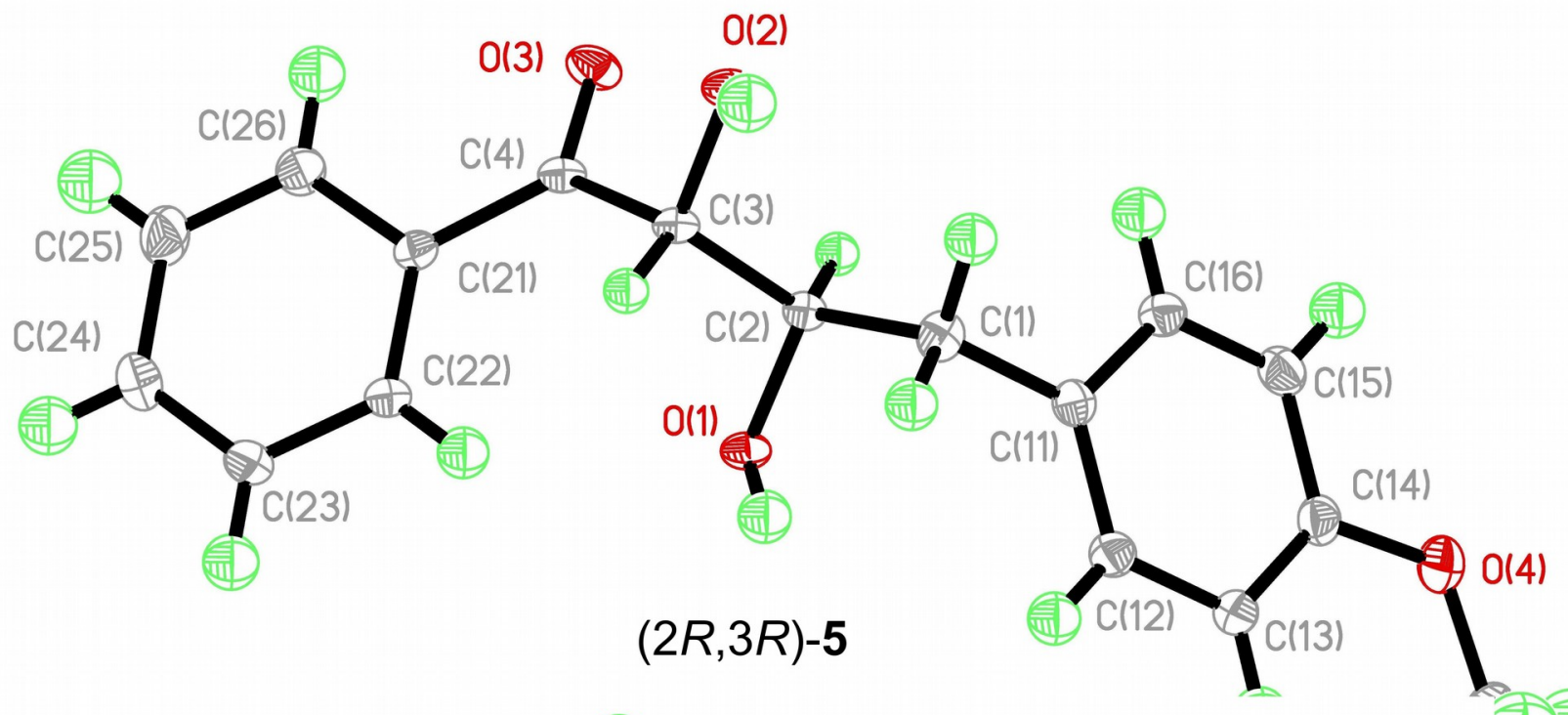

(b)

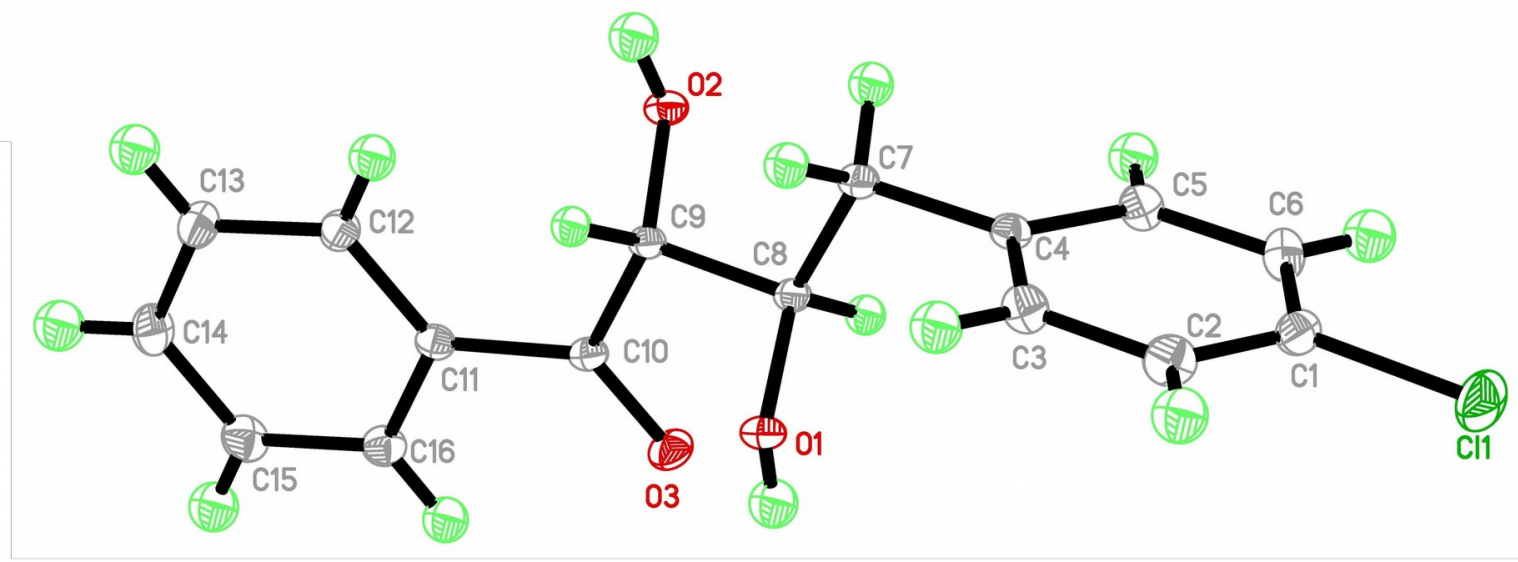

$(2 R, 3 R)-6$

(c)

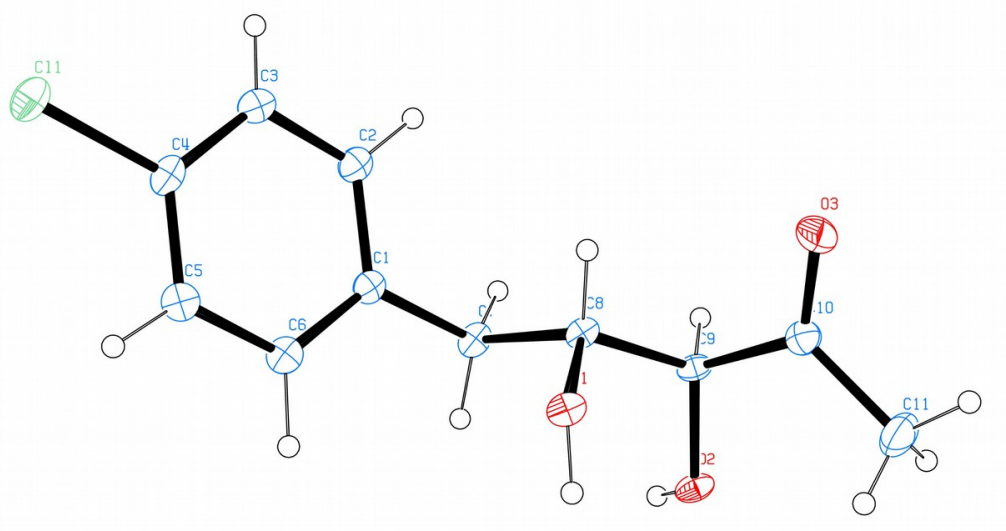

$$
(3 S, 4 R)-12
$$

Figure 4. ORTEP plots of crystal structures of (a), (2R,3R-5), (b), (2R,3R-6) and (c), (3S,4R-12). The ellipsoid contour probabilities are set at $15 \%$ in all three cases. 
Experimental: Compound 5:

The crystals were obtained by recrystallization from minimal amount of methanol:hexane $=1: 2$ solvent. Formula $\mathrm{C}_{17} \mathrm{H}_{18} \mathrm{O}_{4}, \mathrm{Mw}=286,31 \mathrm{~g} / \mathrm{mol}$, Monoclinic, Space Group P2(1), $\mathrm{a}=5.6203(3), \mathrm{b}=$ 8.9365(5), $\mathrm{c}=14.7908(10) \AA, \beta=92.213(3)^{\circ}, \mathrm{V}=742.33(8) \AA^{3} .10649$ reflections were collected using graphite monochromated MoK $\alpha$ radiation, $\lambda=0.71073 \AA$ at room temperature $(296(2) \mathrm{K}) \mathrm{using}$ Bruker D8 SMART Apex-II CCD diffractometer in the angle range $1.38<\theta<29.35^{\circ}$ with data completeness $94.9 \%$. All non-hydrogen atoms were found in the initial solution and refined first in isotropic and then anisotropic approximation. The hydrogen atoms were either added by geometric calculation (alkyl, or found in difference Fourier syntheses (hydroxyl), and added to the final refinement in anisotropic approximation. Final convergence factors were R1 $=0.0360$, wR2 $=0.1049$ for 2926 observed reflections Fo $>4 \operatorname{sig}(\mathrm{Fo})$ and R1 $=0.0526$, wR2 $=0.1219$ for all 3747 [R(int) $=$ 0.0258] independent reflections.

Compound 6: The crystals were obtained by slow evaporation in air from solution in a minimal amount of methanol:hexane $=1: 2$ solvent. Formula $\mathrm{C}_{16} \mathrm{H}_{15} \mathrm{ClO}_{3}, \mathrm{Mw}=290.73 \mathrm{~g} / \mathrm{mol}$, Orthorhombic, Space Group Pbcn, $\mathrm{a}=8.345(3), \mathrm{b}=11.250(3), \mathrm{c}=30.833 \AA, \mathrm{V}=2894.6(15) \AA^{3} .23715$ reflections were collected using graphite monochromated MoK $\alpha$ radiation, $\lambda=0.71073 \AA$ at room temperature $(296(2)$ K) using Bruker D8 SMART Apex-II CCD diffractometer in the angle range $2.64<\theta<23.82^{\circ}$ with data completeness $99.7 \%$. All non-hydrogen atoms were found in the initial solution and refined first in isotropic and then anisotropic approximation. The hydrogen atoms were either added by geometric calculation (alkyl, or found in difference Fourier syntheses (hydroxyl), and added to the final refinement in anisotropic approximation. Final convergence factors were R1 $=0.0344$, wR $2=0.0879$ for 1754 observed reflections Fo $>4 \operatorname{sig}(\mathrm{Fo})$ and $\mathrm{R} 1=0.0482$, wR2 $=0.0983$ for all 2218 [R(int) $=$ 0.0329] independent reflections.

Compound 12: The crystals were obtained by slow evaporation in air from solution in a minimal amount of pure methanol. Formula $\mathrm{C}_{11} \mathrm{H}_{13} \mathrm{ClO}_{3}, \mathrm{Mw}=228.66 \mathrm{~g} / \mathrm{mol}$, Monoclinic, Space Group P2(1)/n, $a=14.851(15), b=4.703(5), c=16.195(16) \AA, \beta=107.694(12)^{\circ}, V=1077.8(19) \AA^{3} .7459$ reflections were collected using graphite monochromated MoK $\alpha$ radiation, $\lambda=0.71073 \AA$ at room temperature $(296(2)$ K) using Bruker D8 SMART Apex-II CCD diffractometer in the angle range $2.229<\theta<25.245^{\circ}$ with data completeness $99.3 \%$. All non-hydrogen atoms were found in the initial solution and refined first in isotropic and then anisotropic approximation. The hydrogen atoms were either added by geometric calculation (alkyl, or found in difference Fourier syntheses (hydroxyl), and added to the final refinement in anisotropic approximation. Final convergence factors were R1 $=0.0529, \mathrm{wR} 2=0.1263$ for 1485 observed reflections $\mathrm{Fo}>4 \operatorname{sig}(\mathrm{Fo})$ and $\mathrm{R} 1=0.0705$, wR2 $=0.1322$ for all 1944 [R(int) $=$ 0.0787] independent reflections. 


\section{SUPPLEMENTARY REFERENCES}

(S1) Ma, H.; Engel, S.; Enugala, T. R.; Al-Smadi, D.; Gautier, C.; Widersten, M. New Stereoselective Biocatalysts for Carboligation and Retro-Aldol Cleavage Reactions Derived from D-Fructose 6-Phosphate Aldolase. Biochemistry 2018, 57, 5877-5885.

(S2) Concia, A. L.; Lozano, C.; Castillo, J. A.; Parella, T.; Joglar, J.; Clapés, P. D-Fructose-6phosphate Aldolase in Organic Synthesis: Cascade Chemical-Enzymatic Preparation of Sugar-Related Polyhydroxylated Compounds. Chem. Eur. J. 2009, 15, 3808-3816.

(S3) Miyoshi, N.; Takeuchi, S.; Ohgo, Y. The SmI 2 Mediated Cross-Coupling Reaction of Aldehydes With $\alpha$-Diketones in Their Aqueous Forms. Chem. Lett. 1993, 2129-2132.

(S4) Bas, S.; Woźniak, Ł.; Cygan, J.; Mlynarski, J. Asymmetric syn-Aldol Reaction of $\alpha$-Hydroxy Ketones with Tertiary Amine Catalysts. Eur. J. Org. Chem. 2013, 6917-6923. 